\title{
1,8-cineol potentiates IRF3-mediated antiviral response in human stem cells and an ex vivo model of rhinosinusitis
}

Article

Accepted Version

Müller, J., Greiner, J. F. W., Zeuner, M., Brotzmann, V., Schäfermann, J., Wieters, F., Widera, D., Sudhoff, H., Kaltschmidt, B. and Kaltschmidt, C. (2016) 1,8-cineol potentiates IRF3-mediated antiviral response in human stem cells and an ex vivo model of rhinosinusitis. Clinical Science. ISSN 0143-5221 doi: https://doi.org/10.1042/CS20160218 Available at https://centaur.reading.ac.uk/64212/

It is advisable to refer to the publisher's version if you intend to cite from the work. See Guidance on citing.

To link to this article DOI: http://dx.doi.org/10.1042/CS20160218

Publisher: Portland Press

All outputs in CentAUR are protected by Intellectual Property Rights law, including copyright law. Copyright and IPR is retained by the creators or other copyright holders. Terms and conditions for use of this material are defined in the End User Agreement. 


\section{CentAUR}

Central Archive at the University of Reading

Reading's research outputs online 


\title{
1,8-cineole potentiates IRF3-mediated antiviral response in human stem cells and an ex vivo model of rhinosinusitis
}

\author{
Janine Müller ${ }^{1,2,3^{*}}$, Johannes FW Greiner ${ }^{1,2^{*}}$, Marie Zeuner ${ }^{2,4^{*}}$, Viktoria Brotzmann ${ }^{1,2}$, \\ Johanna Schäfermann $^{1,2}$, Frederique Wieters ${ }^{1,2}$, Darius Widera ${ }^{2,4}$, Holger Sudhoff ${ }^{1 \star}$, Barbara \\ Kaltschmidt ${ }^{2,3^{*}}$ and Christian Kaltschmidt ${ }^{2 *}$
}

${ }^{1}$ Department of Otolaryngology, Head and Neck Surgery, Klinikum Bielefeld, D-33604 Bielefeld, Germany

${ }^{2}$ Department of Cell Biology, University of Bielefeld, 33619 Bielefeld, Germany

${ }^{3}$ AG Molecular Neurobiology, University of Bielefeld, 33619 Bielefeld, Germany

${ }^{4}$ present address: Reading School of Pharmacy, University of Reading, PO Box 226, Whiteknights, Reading RG6 6AP, Berkshire, United Kingdom

*Authors contributed equally to this work.

${ }^{\#}$ Corresponding Author:

Christian Kaltschmidt,

Department of Cell Biology

University of Bielefeld, Universitätsstr. 25

D-33501 Bielefeld, Germany

Tel.: + 495211065625

Mail: c.kaltschmidt@uni-bielefeld.de

Short title: 1,8-cineole potentiates antiviral response

Keywords: Human ex vivo model, IRF3, NF-kB, 1,8-cineole, common cold, Poly(I:C) 


\section{Abstract}

Common cold is one of the most frequent human inflammatory diseases caused by viruses and can facilitate bacterial super-infections resulting in sinusitis or pneumonia. The active ingredient of the drug Soledum, 1,8-cineole, is commonly applied for treating inflammatory diseases of the respiratory tract. However, the potential of 1,8-cineole for treating primary viral infections of the respiratory tract remains unclear.

In the present study, we demonstrate for the first time that 1,8-cineole potentiates Poly(I:C)induced activity of the anti-viral transcription factor Interferon Regulatory Factor 3 , while simultaneously reducing pro-inflammatory NF-KB-activity in human cell lines, inferior turbinate stem cells (ITSCs) and ex vivo cultivated human nasal mucosa. Co-treatment of cell lines with Poly(I:C) and 1,8-cineole resulted in significantly increased IRF3 reporter gene activity compared to Poly $(\mathrm{I}: \mathrm{C})$ alone, whereas NF-KB-activity was reduced. Accordingly, 1,8cineole- and Poly(I:C)-treatment led to increased nuclear translocation of IRF3 in ITSCs and a human ex vivo model of rhinosinusitis compared to the Poly(l:C)-treated approach. Nuclear translocation of IRF3 was significantly increased in ITSCs and slice cultures treated with LPS and 1,8-cineole compared to the LPS-treated cells mimicking bacterial infection.

Our findings strongly suggest that 1,8-cineole potentiates the antiviral activity of IRF3 in addition to its inhibitory effect on pro-inflammatory NF-KB-signalling and may thus broaden its field of application. 


\section{Summary statement}

Respiratory diseases are highly frequent and can be treated with 1,8-cineole. We show that 1,8-cineole potentiates antiviral activity in cultivated human nasal stem cells, and nasal tissue. The combination with its anti-inflammatory effect suggests new treatment strategies against common cold. 


\section{Introduction}

The common cold syndrome is one of the most frequent inflammatory diseases, averagely affecting an adult two to four times per year (reviewed in (1)). Infection of the respiratory tract by rhinoviruses (2), or to a lesser extent by coronaviruses or influenza viruses is followed by typical symptoms ranging from sneezing, sore throat, cough and nasal congestion to tiredness and malaise $(3,4)$. In addition, common cold has been reported to lead to an increase of acute exacerbations in patients with asthma and chronic obstructive pulmonary disease (COPD) (5-7). The damage of respiratory epithelium during viral infection further facilitates bacterial infections of the respiratory tract and subsequent inflammatory diseases like sinusitis and pneumonia (reviewed in (1)).

Natural, plant-derived monoterpenoids are commonly applied for treatment of inflammatory diseases of the respiratory tract (8). Initially identified by Cloez in 1870 as the dominant portion of Eucalyptus globulus oil (9), the monoterpenoid 1,8-cineole was described to have an anti-bacterial activity $(10,11)$ as well as anti-inflammatory effects in animal models of allergic airway inflammation $(12,13)$ and acute pulmonary inflammation (14). 1,8-cineole is currently therapeutically applied as the active ingredient of the drug Soledum. Placebocontrolled, double blind trials demonstrated an effective treatment of acute sinusitis with 1,8cineole in 152 patients (15). Worth and colleagues further demonstrated 1,8-cineole to improve lung function and reduce exacerbations in 242 patients suffering from COPD (16). Likewise, Juergens et al. showed beneficial effects of 1,8-cineole in 12 of 16 patients with bronchial asthma $(17,18)$. Indicating a potential molecular mechanism by cytokine inhibition, 1,8-cineole reduced the production of pro-inflammatory cytokines TNFa and IL1 $\beta$ in human monocytes (19). We extended these findings by demonstrating that 1,8-cineole inhibits the activity of the transcription factor nuclear factor kappa light chain enhancer of activated Bcells (NF-KB), a key mediator of pro-inflammatory signalling. In particular, we showed a 1,8cineole-dependent reduction of nuclear translocation of NF-kB p65 and decreased NF-kBdependent transcriptional activity (20). This novel mode of action was recently confirmed by Zhao and co-workers, who showed a NF-KB-associated reduction of pro-inflammatory cytokines after 1,8-cineole-treatment in the mouse system in vivo (14). Despite these promising effects against bacteria-induced inflammation, the potential effect of 1,8-cineole for treating the predisposing viral infection remains unclear. In the present study, we applied the double-stranded RNA analogue Poly(I:C) (polyinosinic:polycytidylic acid) to mimic viral infection in vitro and ex vivo. Poly $(\mathrm{I}: \mathrm{C})$ is broadly described to induce antiviral responses in a broad variety of cell types such as human alveolar, corneal and bronchial epithelial cells (21, 22) as well as in the lung of mice (23). Poly(l:C) is recognized by Toll-like receptor 3 (TLR3), in turn leading to a cellular antiviral response via activation of the MyD88-independent signalling pathway culminating in activation of IRF3 and production of type I interferons (IFN). In addition to activation of IRF3, MyD88-independent signalling results in a late and weak activation of NF-KB followed by a moderate release of pro-inflammatory cytokines $(24,25)$. Notably, Wang et al. reported in 2009 a TLR3-mediated recognition of rhinoviral dsRNA intermediates in rhinovirus-infected airway epithelial cells (26), highlighting the suitability of Poly $(I: C)$ to mimic rhinoviral infection. In the present study, we determined potential effects of 1,8-cineole on antiviral IRF3-activity using human cell lines and human nasal stem cells isolated from the inferior turbinate. ITSCs represent a promising cellular model system due to their easy expandability and their endogenous niche within the respiratory epithelium (27, 28). Next to cellular models, we described very recently the successful application of ex vivo cultivated human nasal slices from the inferior turbinate as a novel model system of the late phase of rhinosinusitis. Here, treatment with 1,8-cineole significantly reduced the amount of Alcian Blue-stained mucin within goblet cells. Accordingly, we observed a significant reduction of MUC2 gene expression in ex vivo cultivated nasal slices accompanied by attenuated expression levels of TNFa (29). In the present study, we demonstrate for the first time that 1,8-cineole leads to elevated levels of antiviral IRF3-activity in human cell lines, ITSCs as well as in ex vivo cultivated human nasal tissue in a viral mimic model. In particular, Poly(l:C)-treatment of human cell lines resulted in increased activity, nuclear 
translocation and respective target gene expression of IRF3 and NF-KB. Exposure to Poly(I:C) and 1,8-cineole led to significantly increased IRF3-activity, accompanied by reduced nuclear translocation of NF-KB p65 and diminished NF-KB-activity. Notably, nuclear translocation of IRF3 was significantly increased in ITSCs and nasal slice cultures treated with Poly $(\mathrm{I}: \mathrm{C})$ and 1,8-cineole in comparison to the Poly $(\mathrm{I}: \mathrm{C})$-treated approaches. Moreover, LPS-treatment of human nasal slice cultures led to an increased activity of IRF3, which was further significantly increased after co-treatment with 1,8-cineole. 


\section{Materials and Methods}

\section{Cell culture}

Human cell lines U373 and U251 were cultivated in DMEM High Glucose (Sigma-Aldrich, cat. No. D5671, Taufkirchen, Germany) containing 1\% L-Glu (200 mM; Sigma-Aldrich, Taufkirchen, Germany) and $10 \%$ fetal calf serum (FCS, lot: 126K3398, Sigma-Aldrich, Taufkirchen, Germany) in a humidified incubator (Binder, Tuttlingen, Germany) at $37^{\circ} \mathrm{C}$ and $5 \% \mathrm{CO}_{2}$. ITSCs were isolated from inferior turbinates obtained during nasal surgery after an informed consent according to local and international guidelines (Bezirksregierung Detmold/ Münster). Isolation and further experimental procedures were ethically approved by the ethics commission of the Ärztekammer Westfalen-Lippe and the medical faculty of the Westfälische Wilhems-Universität (Münster, Germany) (approval reference number 2012-15fS). Isolation and cultivation procedures were performed as described in Hauser et al. (27). U373 and U251 cells as well as ITSCs were treated with Poly(I:C) (polyinosinic-polycytidylic acid sodium salt, $100 \mu \mathrm{g} / \mathrm{ml}$, cat. No. P1530, Sigma Aldrich), LPS (Lipopolysaccharides, 1 $\mu \mathrm{g} / \mathrm{ml}$, rough strains from Salmonella enterica Re 595, cat. no. L9764, Sigma-Adrich St. Louis, MO, USA), or LPS/Poly (I:C) and 1,8-cineole $\left(10^{-4} \mathrm{M}\right.$, prepared as described in Greiner et al (20), Klosterfrau Healthcare Group, Cassella-med GmbH \& Co. KG, Cologne, Germany).

\section{Tissue culture of nasal turbinate slices}

Human nasal inferior turbinates were isolated during nasal surgery after an informed consent according to local and international guidelines (Bezirksregierung Detmold/ Münster). Isolation and further experimental procedures were ethically approved by the ethics commission of the Ärztekammer Westfalen-Lippe and the medical faculty of the Westfälische WilhemsUniversität (Münster, Germany) (approval reference number 2012-15-fS). Sliced Inferior turbinate tissue $(200 \mu \mathrm{m}$ thickness) was transferred to culture plate inserts $(0.4 \mu \mathrm{m}$ nitrocellulose membrane, Millipore/Greiner, Billerica, MA, USA) and cultivated at the interface of air and B-ALI differentiation medium (Lonza, Basel, Switzerland) as previously described (29). Nasal slices were cultured for at least one week followed by treatment with LPS (100 $\mathrm{ng} / \mathrm{ml}$, rough strains from Salmonella enterica Re 595, cat. no. L9764, Sigma-Adrich St. Louis, MO, USA), or co-treatment with LPS and 1,8-cineole $\left(10^{-4} \mathrm{M}\right.$, Klosterfrau Healthcare Group, Cassella-med $\mathrm{GmbH}$ \& Co. KG, Cologne, Germany) for $24 \mathrm{~h}$ followed by immunohistochemistry as described below. Treatment of nasal slice cultures with Poly(l:C)$\left(100 \mu \mathrm{g} / \mathrm{ml}\right.$, Sigma Aldrich) or Poly $(\mathrm{I}: \mathrm{C})$ and 1,8-cineole $\left(10^{-4} \mathrm{M}\right.$, Klosterfrau Healthcare Group, Cassella-med $\mathrm{GmbH}$ \& Co. KG) was performed for $2 \mathrm{~h}$ and $4 \mathrm{~h}$ followed by immunohistochemistry as described below.

\section{Transient transfection and gene reporter assays}

U373 and U251 cells were transfected with $2.2 \mu \mathrm{g}$ pRL-CMV (Promega Cooperation, Mannheim, Germany) and $1.1 \mu \mathrm{g} \mathrm{TK}(\mathrm{NF}-\mathrm{KB})_{6}$ LUC (30) for NF-KB reporter gene assays or $2.2 \mu \mathrm{g}$ pRL-CMV (Promega Cooperation, Mannheim, Germany) as well as $1 \mu \mathrm{g}$ IRF3-Gal4 and $1 \mu \mathrm{g}$ UAS-LUC (kindly provided by Katherine A. Fitzgerald, Department of Medicine, University of Massachusetts Medical School, Worcester, USA). Transfection was performed using rat NSC Nucleofector Kit (Amaxa Biosystems, Lonza Group AG, Basel, Switzerland) and Nucleofector II device (Lonza Group) according to manufacturer's guidelines. FPred (1.5 $\mu \mathrm{g}$, Lonza Group, Basel, Switzerland) or pmaxGFP (0.3 $\mu \mathrm{g}$, Lonza Group, Basel, Switzerland) served as transfection control. $24 \mathrm{~h}$ after transfection, U373 and U251 cells were treated with Poly(I:C) (Sigma Aldrich), LPS $(1 \mu \mathrm{g} / \mathrm{ml}$, rough strains from Salmonella enterica Re 595, Sigma-Adrich), or combinations of LPS/Poly(I:C) and 1,8-cineole $\left(1 \times 10^{-4} \mathrm{M}\right.$ or $2 \times 10^{-4} \mathrm{M}$ prepared as described in Greiner et al (20), Klosterfrau Healthcare Group) for 24 h. Luciferase activity was subsequently assessed by applying Dual-Luciferase® Reporter Assay System (Promega Corporation, cat. no. E1960) according to manufacturer's 
guidelines. Statistical analysis was performed using GraphPad Prism software (GraphPad Software, La Jolla, CA, USA), bioluminescence of constitutively active Renilla luciferase ( $p R L-C M V$ vector) served for normalization.

\section{Reverse transcription PCR}

Total RNA was isolated from untreated and Poly(I:C)-treated U251 cells, and peripheral blood monocytes (PBMCs) as described above using RNeasy Mini Kit (QIAGEN, Hilden, Germany) according to manufacturer's guidelines or via phenol-chloroform extraction. PBMCs (no. 090928AUK136/02) were kindly provided by Cellular Therapy Centre, Medical School Hannover, Hannover, Germany (informed consent was provided to Klinikum Bielefeld, Bielefeld, Germany). Quality and concentration of RNA was determined using Nanodrop UV spectrophotometry followed by cDNA synthesis via application of First Strand cDNA Synthesis Kit (Thermo Fisher Scientific, cat. No. K1612, Darmstadt, Germany) according to manufacturer's guidelines. PCR was performed using GoTaq Polymerase (Promega Cooperation, Mannheim, Germany) according to manufacturer's guidelines. For primer sequences $(0.5 \mu \mathrm{M}$, Metabion, Martinsried, Germany) see Table 1.

\section{Real Time PCR}

Total RNA was isolated from ITSCs treated as described above using RNeasy Mini Kit (QIAGEN, Hilden, Germany) followed by cDNA synthesis with qSqript cDNA Synthesis Kit (Quanta, Gaithersburg, MD, USA) according to manufacturer's guidelines. All qPCR reactions were performed as triplicate using 5x EvaGreen® QPCR-Mix II (Bio-Budget Technologies $\mathrm{GmbH}$, Krefeld, Germany) according to manufacturer's guidelines and assayed with a Rotor Gene 6000 (QIAGEN). Primer sequences $(0.5 \mu \mathrm{M}$, Metabion, Martinsried, Germany) were CCCTCGCTGTCATCCTCATT (RANTES forward), ACGACTGCTGGGTTGGAG (RANTES reverse), CTGCACCACCAACTGCTTAG (GAPDH forward) and GTCTTCTGGGTGGCAGTGAT (GAPDH reverse).

\section{Immunocytochemistry}

For immunocytochemistry, U251 cells, U373 cells, and ITSCs treated as described above were fixed using $4 \%$ paraformaldehyde (PFA, $4 \%$ paraformaldehyde, $100 \mathrm{mM} \mathrm{NaH}_{2} \mathrm{PO}_{4}$, $0.4 \mathrm{mM} \mathrm{CaCl}_{2}$ ) for 20 minutes followed by permeabilization and blocking with $0.02 \%$ PBT (0.02\% TritonX-100 (Sigma-Aldrich cat. No. T8787, Taufkirchen, Germany) in PBS) comprising $5 \%$ goat serum (Dianova, Hamburg, Germany). Primary antibodies anti-NF-kBp65 (sc-372 or sc8008, Santa Cruz Biotechnologies) or anti-IRF3 (sc-9082, Santa Cruz Biotechnologies) were applied for $1 \mathrm{~h}$. Respective secondary fluorochrome-conjugated antibodies (A21428, A21422, A21201, Molecular Probes, Göttingen, Germany) were subsequently added for $1 \mathrm{~h}$ under exclusion of light. Nuclear counterstaining was performed by applying 4',6-Diamidin-2-phenylindol (DAPI; 1:2000, Life Technologies, Darmstadt, Germany) for 15 min followed by covering with mowiol. Fluorescence imaging was done using confocal scanning microscopy (LSM 780, Carl Zeiss, Jena, Germany) and ZEN software (Carl Zeiss). Image processing and analysis were performed using Fiji (31) followed by statistical analysis with GraphPad Prism software (GraphPad Software, La Jolla, CA, USA).

\section{Immunohistochemistry}

Nasal slices cultivated and treated as described above were removed from the culture inserts followed by preparation of $10 \mu \mathrm{m}$ thick cryosections. For immunohistochemistry, $4 \%$ PFA was applied for 20 minutes followed by permeabilization and blocking with $0.1 \%$ PBT (Sigma-Aldrich) comprising $5 \%$ goat serum (Dianova) and addition of primary antibodies anti-NF-kB-p65 (sc-372 or sc8008, Santa Cruz Biotechnologies), anti-IRF3 (sc-9082, Santa Cruz Biotechnologies) or anti-CK14 (sc-7156, Santa Cruz Biotechnologies) for $2 \mathrm{~h}$. Respective secondary fluorochrome-conjugated antibodies (A21428, A21422, A21201, Molecular Probes) were subsequently applied for $1 \mathrm{~h}$ under exclusion of light. Nuclear 
counterstaining was done using DAPI (1:2000, Life Technologies) for 15 min followed by covering with mowiol. Fluorescence imaging was done via confocal scanning microscopy (LSM 780, Carl Zeiss) and ZEN software (Carl Zeiss) followed by image processing and analysis using Fiji (31). Statistical analysis was performed using GraphPad Prism software (GraphPad Software). 


\section{Results}

\section{Poly(I:C)-driven mimicry of viral infection increases activity of NF-KB and IRF3}

Assessing the presence of protein transcripts relevant for NF-KB- and IRF3-signalling in U251 cells, we showed expression of Toll-like receptor 3 and 4 (TLR3, TLR4), cluster of differentiation 14 (CD14), Lymphocyte antigen 96 (MD2), Myeloid differentiation primary response gene 88 (MYD88), TIR-domain-containing adapter-inducing interferon- $\beta$ (TRIF), Toll/interleukin-1 receptor domain-containing adapter protein (TIRAP) and TRIF related adapter molecule (TRAM) (Fig. 1A). In order to mimic viral infection in U251 cells, we applied the double strand RNA analogue Poly $(I: C)$ to simulate the presence of dsRNA replication intermediates of single strand RNA viruses $(24,26)$. U251 cells transiently transfected with a dual luciferase NF-KB-reporter system showed a significant increase in luciferase activity after treatment with increasing concentrations of Poly $(\mathrm{I}: \mathrm{C})(25-1000 \mu \mathrm{g} / \mathrm{ml})$ in comparison to untreated control. In addition, we observed significantly augmented luciferase activities compared to control in response to Poly $(\mathrm{I}: \mathrm{C})(25-1000 \mu \mathrm{g} / \mathrm{ml})$ in U251 cells transiently transfected with a IRF3-driven luciferase reporter system (Fig. 1B).

Significantly increased nuclear translocation of IRF3 and NF-kB p65 after Poly(I:C)treatment is accompanied by an increased expression of IRF3 and NF-KB target genes

Validating the increase in sustained IRF3- and NF-KB-activity, we showed an augmented nuclear translocation of IRF3 and NF-KB p65 in U251 cells after Poly(I:C)-treatment compared to the control (Fig. 1C, Fig. S1, Fig. S2). Quantification of immunocytochemical stainings confirmed the increase in the amount of nuclear IRF3 after $2 \mathrm{~h}$ and $4 \mathrm{~h}$ of Poly(l:C)treatment. Accordingly, significantly elevated nuclear translocation of NF-kB p65 was observed in U251 cells treated with Poly $(\mathrm{l}: \mathrm{C})$ for $2 \mathrm{~h}$ in comparison to control (Fig. 1D). RTPCR analysis further demonstrated increased expression of IRF3 target genes Regulated on Activation, Normal T cell Expressed and Secreted (RANTES) and interferon- $\beta$ (IFN- $\beta$ ). In addition, we detected an elevated expression of the NF-KB target gene tumour necrosis factor $\alpha$ (TNF $\alpha)$ in Poly(I:C)-treated U251 cells compared to untreated control (Fig. 1E).

\section{Poly(I:C)-induced activity of IRF3 is further increased by co-treatment with 1,8-cineole}

To investigate potential effects of 1,8-cineole on IRF3 after Poly(I:C)-mediated simulation of viral infection we transiently transfected U373 cells with a dual IRF3 luciferase reporter system. Poly(I:C)-treatment of U373 cells transiently transfected with the dual IRF3-reporter system led to significantly increased luciferase activity in comparison to control. Although we observed no effects of 1,8-cineole alone (Fig. S3A), combination of Poly(I:C) and 1,8-cineole led to a further increase of luciferase activity if compared to Poly(l:C)-treated cells (Fig. 2A).

\section{1,8-cineole leads to strongly reduced nuclear translocation of NF-kB p65 as well as significantly reduced levels of NF-kB-activity after Poly(I:C)-treatment}

Next, we determined the effects of 1,8-cineole on NF-kB after Poly(l:C) stimulation. Luciferase activity in U251 cells transiently transfected with a dual NF-kB-reporter system showed an increase of NF-kB-activity after Poly(I:C)-treatment in comparison to control. Cotreatment with 1,8-cineole resulted in significantly decreased luciferase activity compared to Poly(I:C)-treated cells (Fig. $2 A$ ), demonstrating the reduction of pro-inflammatory NF-KBactivity by 1,8-cineole in a model of viral infection. Treatment of U373 cells with Poly(I:C) similarly resulted in increased nuclear translocation of NF-kB p65 compared to the untreated control. Moreover, we observed a significantly decreased nuclear localization of NF-KB p65 after exposure of U373 cells to Poly(I:C) and 1,8-cineole in comparison to Poly(I:C)stimulated cells (Fig. 2C-D). No differences to control were observed in cell treated with 1,8cineole alone (Fig. S3B). 


\section{1,8-cineole-treatment results in significantly augmented IRF3-activity and reduced activity of NF-kB p65 after LPS-stimulation}

In order to investigate the activity of IRF3 after LPS-treatment, U373 cells were transiently transfected with a dual IRF3-reporter system. Here, we detected significantly higher luciferase bioluminescence after LPS-treatment compared to untreated control. U373 cells co-treated with LPS and 1,8-cineole showed a further increase in IRF3-activity in comparison to cells treated with LPS alone (Fig. 2B).

A dual luciferase reporter gene assay revealed significantly increased NF-KB-activity after treatment with LPS in comparison to control. Co-treatment with 1,8-cineole resulted in a significant decrease in luciferase activity compared to the cells exposed to LPS alone (Fig. $2 \mathrm{~B})$. In accordance with our previous findings (20), we observed significantly reduced amounts of nuclear NF-KB p65 after treatment with 1,8-cineole and LPS compared to LPSstimulation alone (data not shown).

\section{Poly(I:C) leads to increased nuclear translocation of IRF3 and NF-KB in ITSCs}

With regards to the endogenous environment of rhinosinusitis, we applied stem cells isolated from the respiratory epithelium of adult human inferior turbinate (Fig. $3 A-B$ ) to further determine potential effects of 1,8-cineole on the activity of IRF3 and NF-KB. Validating the suitability of ITSCs to investigate Poly(I:C)- and LPS-induced activation of IRF3 and NF-KB, we showed expression of TLR3 and TLR4 in ITSCs isolated from three independent donors (Fig. 3C). Exposure of ITSCs to Poly(I:C) for $2 \mathrm{~h}$ resulted in significantly increased nuclear translocation of IRF3 accompanied by highly elevated amounts of nuclear localized NF-KB p65 in comparison to control (Fig 3D-F).

Co-treatment of ITSCs with Poly(I:C) and 1,8-cineole results in increased IRF3-activity accompanied by significantly reduced activity of NF-kB

ITSCs were co-treated with 1,8-cineole and Poly $(\mathrm{I}: \mathrm{C})$ as described above and subjected to immunocytochemical analysis of nuclear IRF3 and p65. Here, co-treatment of ITSCs with Poly $(I: C)$ and 1,8-cineole led to significantly increased nuclear translocation of IRF3 in comparison to Poly(I:C)-stimulation (Fig. 3D-E). However, a significant decrease in the amount of nuclear localized NF-KB p65 was observed in ITSCs exposed to Poly(I:C) and 1,8cineole compared to Poly(I:C)-treated cells (Fig. 3D,3F).

\section{1,8-cineole leads to significantly decreased nuclear localization of NF-kB p65 in LPS- treated ITSCs}

ITSCs were exposed to LPS to mimic bacterial infection common during late rhinosinusitis. LPS-treatment of ITSCs for $2 \mathrm{~h}$ led to an increased nuclear translocation of NF-kB p65 compared to control (Fig. 4A). Co-treatment with 1,8-cineole resulted in a significant decrease of nuclear NF-KB p65 in comparison to Poly(I:C)-stimulation (Fig. 4B). Notably, we observed no changes of nuclear translocation of IRF3 and NF-KB after treatment with 1,8cineole alone (Fig. S3C).

\section{Expression of the IRF3-target gene RANTES is elevated in ITSCs after treatment with 1,8-cineole in a model of superinfection}

As a model of superinfection, ITSCs were pre-treated with Poly $(\mathrm{I}: \mathrm{C})$ for $4 \mathrm{~h}$ followed by coexposure to Poly(I:C) and LPS for $20 \mathrm{~h}$. In comparison to control, significantly increased expression levels of the IRF3 target gene RANTES were observed after simulation of superinfection (Fig. 4C). Co-treatment of ITSCs with Poly(I:C), LPS and 1,8-cineole led to further increase in RANTES expression compared to Poly(I:C)/LPS- stimulation (Fig. 4C). 


\section{1,8-cineole leads to increased nuclear IRF3 and decreased nuclear translocation of NF-KB p65 in ex vivo human nasal turbinate slices stimulated with Poly(I:C)}

We investigated potential effects of 1,8-cineole on IRF3-activity in ex vivo cultivated human nasal turbinate tissue treated with $\operatorname{Poly}(\mathrm{I}: \mathrm{C})$. Cultured nasal turbinate tissue remained an intact epithelial layer demonstrated by expression of CK14 at protein level (Fig. S3A). After 2 $\mathrm{h}$ of Poly(I:C)-treatment, turbinate tissue revealed slightly increased amounts of nuclear IRF3, which were further elevated after co-treatment with 1,8-cineole (Fig 5A). Quantification of nuclear fluorescence intensities in the immunohistochemical stainings revealed a statistically significant increase in nuclear translocation of IRF3 after co-treatment of nasal slice cultures with Poly $(\mathrm{I}: \mathrm{C})$ and 1,8-cineole in comparison to control and Poly(I:C)-treated human nasal slices (Fig. 5B). In contrast to the fast kinetics of Poly(l:C)-dependent activation of IRF3 observed in ITSCs (2 h, Fig. 3D-E), Poly(I:C)-treatment of ex vivo cultivated human nasal slices resulted in a delayed, but significantly increased nuclear translocation of IRF3 after $4 \mathrm{~h}$ (Fig 5C). In addition, we observed further increased amounts of nuclear localized IRF3 after co-treatment with Poly(I:C) and 1,8-cineole compared to Poly(I:C)-treated slices (Fig 5C). Statistically significant increase in nuclear IRF3 was observed after co-treatment of nasal slice cultures with Poly $(\mathrm{l}: \mathrm{C})$ and 1,8-cineole in comparison to control (Fig. 5D).

Besides the increased activity of IRF3, we observed significantly increased nuclear translocation of NF-KB in Poly(l:C)-treated nasal slice cultures compared to control after $2 \mathrm{~h}$ (Fig. 6). Co-treatment with 1,8-cineole and $\operatorname{Poly}(\mathrm{l}: \mathrm{C})$ for $2 \mathrm{~h}$ resulted in significantly decreased nuclear NF-KB compared to slices treated with Poly(I:C) alone (Fig. 6).

\section{Co-treatment of nasal slice cultures with 1,8-cineole and LPS leads to nuclear translocation of IRF3 and decrease of nuclear NF-KB}

In a model of late rhinosinusitis, nasal slice cultures were treated with LPS followed by analysis via immunohistochemistry. We observed an increase in nuclear IRF3 after exposure to LPS, and a further increase in nasal slices co-treated with 1,8-cineole (Fig. 7A, middle panels). LPS-treatment resulted in an increased nuclear translocation of NF-KB in human nasal slice cultures, which was highly decreased after co-treatment with 1,8-cineole (Fig. 7A, right panels, Fig. S4A). We quantified the nuclear fluorescence intensities in the immunohistochemical stainings and showed a statistically significant increase in nuclear translocation of IRF3 after co-treatment of nasal slice cultures with LPS and 1,8-cineole in comparison to control (Fig. 7B). The amount of nuclear NF-kB after LPS stimulation was significantly decreased after co-treatment with 1,8-cineole (Fig. 7C, Fig. S4B-C). 


\section{Discussion}

Model systems of airway diseases include cellular models, such as primary cultures and cell lines of human tracheal or nasal epithelium. In an alveolar epithelial cell line and a bronchial epithelial cell line treated with double-stranded RNA and influenza A virus Guillot and coworkers showed immune response via secretion of the cytokines IL-8, RANTES and IFN- $\beta$ (21). Moreover, primary cell cultures of human tracheal or nasal epithelium infected with rhinoviruses further revealed increased levels of viral RNA and a release of infectious particles (32). In the present study, ITSCs were successfully applied as a novel stem cell model of airway diseases. Next to their great potential for regenerative medicine (33), ITSCs are easily expandable and remain their genetic stability during cultivation (28). Notably, these cells are endogenously located within the respiratory epithelium of the human inferior turbinate (27), further emphasizing their applicability for pharmacological research of the upper respiratory tract. Next to these promising cellular model systems, mouse models are broadly used to simulate airway diseases in vivo (34), although potential differences in the upstream signalling of the antiviral response may question the transferability to the human system (35). Facing this challenge, organ slice cultures remain promising alternatives in terms of resembling the endogenous niche. Here, Switalla and colleagues showed normal innate cytokine response to immunomodulators in human precision-cut lung slices (36). Likewise, increased immune responses were observed in human lung slices infected with influenza virus (37), enabling the application of the model system to functionally test inhalable nanoparticle based influenza vaccine (38). Primary human nasal tissue cultures applied in the present study closely resemble the complex architecture of the endogenous niche including an intact ciliated epithelial surface comprising acetyl- $\alpha$-tubulin-positive cilia, a basal membrane and mucus-filled goblet cells (29). Arruda et al. showed replication of human rhinovirus to occur in the upper respiratory tract, in particular within the nasal epithelium and the nasopharynx (39), underlining the suitability of the here applied stem cell and tissue model systems for mimicking rhinoviral infection.

To simulate rhinoviral infection in ex vivo cultivated human nasal tissue as well as human stem cells and cell lines, Poly(l:C) was applied. This dsRNA analogue is described to mediate antiviral responses in a broad range of cell types (21-23) as well as in the mouse system after intraperitoneal administration (40). On molecular level, both rhinoviral dsRNA intermediates and Poly $(\mathrm{I}: \mathrm{C})$ are recognized via TLR3, which in turn leads to activation of the MyD88-independent signalling pathway resulting in recruitment of TRIF (TIR-domaincontaining adapter-inducing interferon- $\beta$ ) and activation of IRF3. Active IRF3-dimers translocate into the nucleus and regulate the expression of IFN- $\beta$ and RANTES, thereby mediating the cellular antiviral response (25). In addition to mediation of the IRF3-activation, TRIF is also able to activate a late and weak NF-KB response through TRAF6. Activation of NF-KB is followed by expression of its target genes including the pro-inflammatory cytokine TNFa. Accordingly, we observed an increase in antiviral IRF3- and pro-inflammatory NF-KBactivity accompanied by elevated expression of IFN- $\beta$, RANTES and TNF $\alpha$ after Poly(I:C)treatment. Co-treatment with Poly(I:C) and 1,8-cineole led to significantly increased IRF3activity, whereas NF-kB-activity was significantly reduced in comparison to Poly(I:C)-treated cells.

These findings are in general accordance with other studies, hence terpenoids are known to possess direct antiviral properties (reviewed in (41)). In particular, $\alpha$-terpinene, $\gamma$-terpinene, a-pinene and also 1,8-cineole were shown to have an antiviral activity against the DNA virus herpes simplex virus type 1 (HSV-1) by directly inactivating free virus particles (42). Chiang and co-workers further described a broad range of antiviral activity of the terpenoid alcohol linalool and the triterpenoid ursolic acid, namely against adenoviruses, hepatitis $B$ virus, coxsackievirus B1 and enterovirus 71 (43).

Next to mimicking viral infection, we applied LPS to simulate secondary bacterial infection common during late rhinosinusitis (44). Consistent with our previous findings $(20,29)$ and the broadly described anti-inflammatory activity of monoterpenoids (reviewed in (45)), LPS- 
treatment led to significantly increased NF-kB-activity, which was significantly decreased after co-treatment with 1,8-cineole. Likewise to Poly(I:C)-mediated MyD88-independent signalling, IRF3 can be activated by LPS in a TRIF-dependent manner. Here, recognition of LPS by the Toll-like receptor 4 (TLR4) is followed by recruitment of TRIF, in turn leading to nuclear translocation of IRF3 and expression of respective target genes (46). In the present study, we observed an increased nuclear translocation of IRF3 in human nasal slice cultures after LPS-stimulation. Co-treatment with 1,8-cineole significantly increased the amount of nuclear IRF3, suggesting an antiviral activity of 1,8-cineole during late rhinosinusitis. Moreover, 1,8-cineole led to significantly elevated expression levels of the IRF-3 target gene RANTES in Poly(I:C)-pre-treated ITSCs after additional co-treatment with LPS and Poly(I:C) mimicking bacterial superinfection.

The potential therapeutic impact of activating IRF3-mediated antiviral responses while simultaneously inhibiting pro-inflammatory NF-KB-signalling was impressively shown by Bartlett and coworkers. In particular, the authors demonstrated reduced inflammation but unchanged antiviral responses in vivo in rhinovirus-infected mice lacking NF-kB-p65. However, Interferon a-receptor 1-deficient mice infected with rhinoviruses showed elevated levels of rhinovirus replication and decreased antiviral responses, suggesting a new therapeutic strategy against rhinoviral infection via reduction of NF-kB-dependent proinflammatory signalling accompanied by increased antiviral IFN-signalling (47). Next to common cold syndromes, rhinovirus infections also increase acute exacerbations in asthma patients (6). Rhinovirus-induced asthma is often accompanied by glucocorticoid resistance in an NF-KB-dependent manner, resulting in inefficient treatment of asthma exacerbations (48). Since 1,8-cineole is already established for treating steroid-dependent asthma (17), the here observed IRF3-dependent anti-viral activity of 1,8-cineole in addition to the already described inhibitory effects on NF-kB-signalling (20) may further broaden its range of application.

In summary, this study demonstrates for the first time that 1,8-cineole, which is clinically approved as the active ingredient of Soledum, activates IRF3-mediated antiviral response in a human ex vivo model of rhinosinusitis. Our findings may broaden the range of clinical applications of 1,8-cineole, particularly in terms of treating the common cold syndrome and related ssRNA virus-dependent airway infections. 


\section{Acknowledgements}

The excellent technical help of Angela Krahlemann-Köhler and Monika Wart is gratefully acknowledged. We thank Katherine A. Fitzgerald, Department of Medicine, University of Massachusetts Medical School, Worcester, USA for kindly providing the IRF3 gene reporter system. 


\section{Declarations of interest}

The authors declare no conflict of interest. This study was sponsored by Klosterfrau Healthcare Group, Cassella-med GmbH \& Co. KG, Cologne, Germany. The study sponsor did not participate in study design and data analysis. 


\section{Funding information}

This study was sponsored by Klosterfrau Healthcare Group, Cassella-med GmbH \& Co. KG, Cologne, Germany. The study sponsor did not participate in study design and data analysis. 


\section{Author contribution statement}

Authors contributed to the work as described below.

Janine Müller: Collection and assembly of data, Data analysis and interpretation, Manuscript writing, Final approval of manuscript

Johannes FW Greiner: Collection and assembly of data, Data analysis and interpretation, Manuscript writing, Final approval of manuscript

Marie Zeuner: Collection and assembly of data, Data analysis and interpretation, Conception and design of the study, Final approval of manuscript

Viktoria Brotzmann: Collection and assembly of data, Final approval of manuscript

Johannes Schäfermann: Collection and assembly of data, Final approval of manuscript

Frederique Wieters: Collection and assembly of data, Final approval of manuscript

Darius Widera: Conception and design of the study, Data analysis and interpretation, Manuscript writing, Final approval of manuscript

Holger Sudhoff: Conception and design of the study, Data analysis and interpretation, Final approval of manuscript

Barbara Kaltschmidt: Conception and design of the study, Data analysis and interpretation, Final approval of manuscript

Christian Kaltschmidt: Conception and design of the study, Data analysis and interpretation, Final approval of manuscript

Janine Müller, Johannes FW Greiner and Marie-Theres Zeuner contributed equally to the work. Holger Sudhoff, Barbara Kaltschmidt and Christian Kaltschmidt likewise contributed equally to the work. 


\section{Clinical perspectives}

Although the common cold syndrome is one of the most frequent virally caused human diseases and can facilitate severe secondary infections like sinusitis or pneumonia, treatment strategies often do not target the underlying viral infection.

Applying ex vivo cultivated human nasal tissue as a model system of rhinosinusitis, we demonstrate here that 1,8-cineole, the active ingredient of the drug Soledum, potentiates the antiviral activity of IRF3 in addition to its inhibitory effect on pro-inflammatory NF-kBsignalling.

The antiviral activity of 1,8-cineole shown in the present study may broaden its range of applications particularly in terms of treating the common cold syndrome and related rhinovirus-dependent airway infections. 


\section{References}

1. Heikkinen T, Jarvinen A. The common cold. Lancet. 2003;361(9351):51-9. Epub 2003/01/09.

2. Arruda E, Pitkaranta A, Witek TJ, Jr., Doyle CA, Hayden FG. Frequency and natural history of rhinovirus infections in adults during autumn. J Clin Microbiol. 1997;35(11):2864-8. Epub 1997/11/14.

3. Gwaltney JM, Jr. Rhinovirus infection of the normal human airway. Am J Respir Crit Care Med. 1995;152(4 Pt 2):S36-9. Epub 1995/10/01.

4. Allan GM, Arroll B. Prevention and treatment of the common cold: making sense of the evidence. CMAJ. 2014;186(3):190-9. Epub 2014/01/29.

5. Nicholson KG, Kent J, Ireland DC. Respiratory viruses and exacerbations of asthma in adults. BMJ. 1993;307(6910):982-6. Epub 1993/10/16.

6. Corne JM, Marshall C, Smith S, Schreiber J, Sanderson G, Holgate ST, et al. Frequency, severity, and duration of rhinovirus infections in asthmatic and non-asthmatic individuals: a longitudinal cohort study. Lancet. 2002;359(9309):831-4. Epub 2002/03/19.

7. George SN, Garcha DS, Mackay AJ, Patel AR, Singh R, Sapsford RJ, et al. Human rhinovirus infection during naturally occurring COPD exacerbations. Eur Respir J. 2014;44(1):87-96. Epub 2014/03/15.

8. Yuan G, Wahlqvist ML, He G, Yang M, Li D. Natural products and anti-inflammatory activity. Asia Pac J Clin Nutr. 2006;15(2):143-52. Epub 2006/05/05.

9. Cloez MS. Étude chimique de l'eucalyptol. Comptes Rendus. 1870;70:687-90.

10. Djenane D, Yanguela J, Amrouche T, Boubrit S, Boussad N, Roncales P. Chemical composition and antimicrobial effects of essential oils of Eucalyptus globulus, Myrtus communis and Satureja hortensis against Escherichia coli 0157:H7 and Staphylococcus aureus in minced beef. Food Sci Technol Int. 2011;17(6):505-15. Epub 2011/11/04.

11. Mulyaningsih S, Sporer F, Reichling J, Wink M. Antibacterial activity of essential oils from Eucalyptus and of selected components against multidrug-resistant bacterial pathogens. Pharm Biol. 2011;49(9):893-9. Epub 2011/05/20.

12. Inoue K, Takano $H$, Shiga A, Fujita $Y$, Makino $H$, Yanagisawa R, et al. Effects of volatile constituents of a rosemary extract on allergic airway inflammation related to house dust mite allergen in mice. Int J Mol Med. 2005;16(2):315-9. Epub 2005/07/14.

13. Bastos VP, Gomes AS, Lima FJ, Brito TS, Soares PM, Pinho JP, et al. Inhaled 1,8cineole reduces inflammatory parameters in airways of ovalbumin-challenged Guinea pigs. Basic Clin Pharmacol Toxicol. 2011;108(1):34-9. Epub 2010/08/21.

14. Zhao C, Sun J, Fang C, Tang F. 1,8-cineol attenuates LPS-induced acute pulmonary inflammation in mice. Inflammation. 2014;37(2):566-72. Epub 2013/11/08.

15. Kehrl W, Sonnemann U, Dethlefsen U. Therapy for acute nonpurulent rhinosinusitis with cineole: results of a double-blind, randomized, placebo-controlled trial. Laryngoscope. 2004;114(4):738-42. Epub 2004/04/06.

16. Worth H, Schacher C, Dethlefsen U. Concomitant therapy with Cineole (Eucalyptole) reduces exacerbations in COPD: a placebo-controlled double-blind trial. Respir Res. 2009;10:69. Epub 2009/07/25.

17. Juergens UR, Dethlefsen U, Steinkamp G, Gillissen A, Repges R, Vetter H. Antiinflammatory activity of 1.8-cineol (eucalyptol) in bronchial asthma: a double-blind placebocontrolled trial. Respir Med. 2003;97(3):250-6. Epub 2003/03/21.

18. Juergens UR. Anti-inflammatory properties of the monoterpene 1.8-cineole: current evidence for co-medication in inflammatory airway diseases. Drug Res (Stuttg). 2014;64(12):638-46. Epub 2014/05/17.

19. Juergens UR, Stober M, Vetter $H$. Inhibition of cytokine production and arachidonic acid metabolism by eucalyptol (1.8-cineole) in human blood monocytes in vitro. Eur $\mathrm{J}$ Med Res. 1998;3(11):508-10. Epub 1998/11/11.

20. Greiner JF, Muller J, Zeuner MT, Hauser S, Seidel T, Klenke C, et al. 1,8-Cineol inhibits nuclear translocation of NF-kappaB p65 and NF-kappaB-dependent transcriptional activity. Biochim Biophys Acta. 2013;1833(12):2866-78. Epub 2013/07/23. 
21. Guillot L, Le Goffic R, Bloch S, Escriou N, Akira S, Chignard M, et al. Involvement of toll-like receptor 3 in the immune response of lung epithelial cells to double-stranded RNA and influenza A virus. J Biol Chem. 2005;280(7):5571-80. Epub 2004/12/08.

22. Kumar A, Zhang J, Yu FS. Toll-like receptor 3 agonist poly(I:C)-induced antiviral response in human corneal epithelial cells. Immunology. 2006;117(1):11-21. Epub 2006/01/21.

23. Stowell NC, Seideman J, Raymond HA, Smalley KA, Lamb RJ, Egenolf DD, et al. Long-term activation of TLR3 by poly $(\mathrm{I}: \mathrm{C})$ induces inflammation and impairs lung function in mice. Respir Res. 2009;10:43. Epub 2009/06/03.

24. Alexopoulou L, Holt AC, Medzhitov R, Flavell RA. Recognition of double-stranded RNA and activation of NF-kappaB by Toll-like receptor 3. Nature. 2001;413(6857):732-8. Epub 2001/10/19.

25. Itoh K, Watanabe A, Funami K, Seya T, Matsumoto M. The clathrin-mediated endocytic pathway participates in dsRNA-induced IFN-beta production. J Immunol. 2008;181(8):5522-9. Epub 2008/10/04.

26. Wang Q, Nagarkar DR, Bowman ER, Schneider D, Gosangi B, Lei J, et al. Role of double-stranded RNA pattern recognition receptors in rhinovirus-induced airway epithelial cell responses. J Immunol. 2009;183(11):6989-97. Epub 2009/11/06.

27. Hauser S, Widera D, Qunneis F, Muller J, Zander C, Greiner J, et al. Isolation of novel multipotent neural crest-derived stem cells from adult human inferior turbinate. Stem cells and development. 2012;21(5):742-56. Epub 2011/12/02.

28. Greiner J, Hauser S, Widera D, Müller J, Qunneis F, Zander C, et al. Efficient animalserum free 3D cultivation method for adult human neural crest-derived stem cell therapeutics. Eur Cell Mater. 2011;22:403-19

29. Sudhoff H, Klenke C, Greiner JF, Muller J, Brotzmann V, Ebmeyer J, et al. 1,8-Cineol Reduces Mucus-Production in a Novel Human Ex Vivo Model of Late Rhinosinusitis. PLoS One. 2015;10(7):e0133040. Epub 2015/07/25.

30. Bachelerie F, Alcami J, Arenzana-Seisdedos F, Virelizier JL. HIV enhancer activity perpetuated by NF-kappa B induction on infection of monocytes. Nature. 1991;350(6320):709-12. Epub 1991/04/25.

31. Schindelin J, Arganda-Carreras I, Frise E, Kaynig V, Longair M, Pietzsch T, et al. Fiji: an open-source platform for biological-image analysis. Nat Methods. 2012;9(7):676-82. Epub 2012/06/30.

32. Lopez-Souza N, Dolganov G, Dubin R, Sachs LA, Sassina L, Sporer H, et al. Resistance of differentiated human airway epithelium to infection by rhinovirus. Am J Physiol Lung Cell Mol Physiol. 2004;286(2):L373-81. Epub 2004/01/09.

33. Müller J, Ossig C, Greiner JF, Hauser S, Fauser M, Widera D, et al. Intrastriatal Transplantation of Adult Human Neural Crest-Derived Stem Cells Improves Functional Outcome in Parkinsonian Rats. Stem cells translational medicine. 2014. Epub 2014/12/07.

34. Hellings PW, Kasran A, Liu Z, Vandekerckhove P, Wuyts A, Overbergh L, et al. Interleukin-17 orchestrates the granulocyte influx into airways after allergen inhalation in a mouse model of allergic asthma. Am J Respir Cell Mol Biol. 2003;28(1):42-50. Epub 2002/12/24.

35. Cavlar T, Deimling T, Ablasser A, Hopfner KP, Hornung V. Species-specific detection of the antiviral small-molecule compound CMA by STING. EMBO J. 2013;32(10):1440-50. Epub 2013/04/23.

36. Switalla S, Lauenstein L, Prenzler F, Knothe S, Förster C, Fieguth HG, et al. Natural innate cytokine response to immunomodulators and adjuvants in human precision-cut lung slices. Toxicology and Applied Pharmacology. 2010;246(3):107-15.

37. Wu W, Booth JL, Duggan ES, Wu S, Patel KB, Coggeshall KM, et al. Innate immune response to $\mathrm{H} 3 \mathrm{~N} 2$ and $\mathrm{H} 1 \mathrm{~N} 1$ influenza virus infection in a human lung organ culture model. Virology. 2010;396(2):178-88. Epub 2009/11/17.

38. Neuhaus V, Schwarz K, Klee A, Seehase S, Forster C, Pfennig O, et al. Functional testing of an inhalable nanoparticle based influenza vaccine using a human precision cut lung slice technique. PLoS One. 2013;8(8):e71728. Epub 2013/08/24. 
39. Arruda E, Boyle TR, Winther B, Pevear DC, Gwaltney JM, Jr., Hayden FG. Localization of human rhinovirus replication in the upper respiratory tract by in situ hybridization. J Infect Dis. 1995;171(5):1329-33. Epub 1995/05/01.

40. Demoulins T, Baron ML, Kettaf N, Abdallah A, Sharif-Askari E, Sekaly RP. Poly (I:C) induced immune response in lymphoid tissues involves three sequential waves of type I IFN expression. Virology. 2009;386(2):225-36. Epub 2009/02/24.

41. Sun IC, Kashiwada Y, Morris-Natschke SL, Lee KH. Plant-derived terpenoids and analogues as anti-HIV agents. Curr Top Med Chem. 2003;3(2):155-69. Epub 2003/02/07.

42. Astani A, Reichling J, Schnitzler P. Comparative study on the antiviral activity of selected monoterpenes derived from essential oils. Phytother Res. 2010;24(5):673-9. Epub 2009/08/05.

43. Chiang LC, Ng LT, Cheng PW, Chiang W, Lin CC. Antiviral activities of extracts and selected pure constituents of Ocimum basilicum. Clin Exp Pharmacol Physiol. 2005;32(10):811-6. Epub 2005/09/22.

44. Kim DH, Jeon EJ, Park SN, Park KH, Park YS, Yeo SW. Effects of a tumor necrosis factor-alpha antagonist on experimentally induced rhinosinusitis. J Biomed Biotechnol. 2011;2011:360457. Epub 2011/07/21.

45. Salminen A, Lehtonen M, Suuronen T, Kaarniranta K, Huuskonen J. Terpenoids: natural inhibitors of NF-kappaB signaling with anti-inflammatory and anticancer potential. Cell Mol Life Sci. 2008;65(19):2979-99. Epub 2008/06/03.

46. Fitzgerald KA, Rowe DC, Barnes BJ, Caffrey DR, Visintin A, Latz E, et al. LPS-TLR4 signaling to IRF-3/7 and NF-kappaB involves the toll adapters TRAM and TRIF. J Exp Med. 2003;198(7):1043-55. Epub 2003/10/01.

47. Bartlett NW, Slater L, Glanville N, Haas JJ, Caramori G, Casolari P, et al. Defining critical roles for NF-kappaB p65 and type I interferon in innate immunity to rhinovirus. EMBO Mol Med. 2012;4(12):1244-60. Epub 2012/11/21.

48. Papi A, Contoli M, Adcock IM, Bellettato C, Padovani A, Casolari P, et al. Rhinovirus infection causes steroid resistance in airway epithelium through nuclear factor kappaB and cJun N-terminal kinase activation. J Allergy Clin Immunol. 2013;132(5):1075-85 e6. Epub 2013/07/23. 
Figures 
Figure 1

A

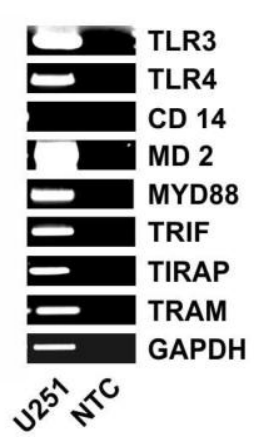

B

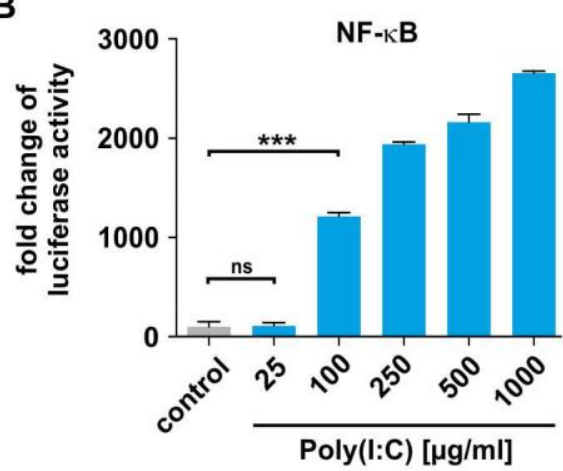

IRF3

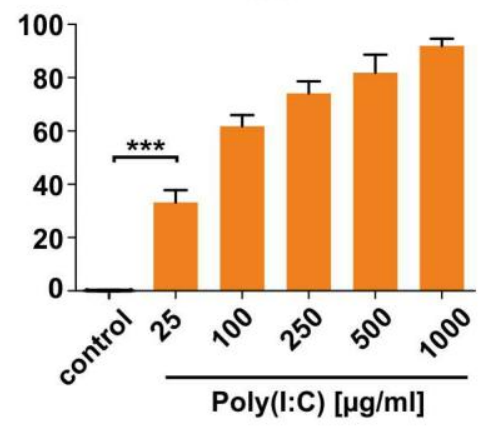

C

$30 \mathrm{~min}$

$1 \mathrm{~h}$

$2 \mathrm{~h}$

$4 \mathrm{~h}$

$24 \mathrm{~h}$
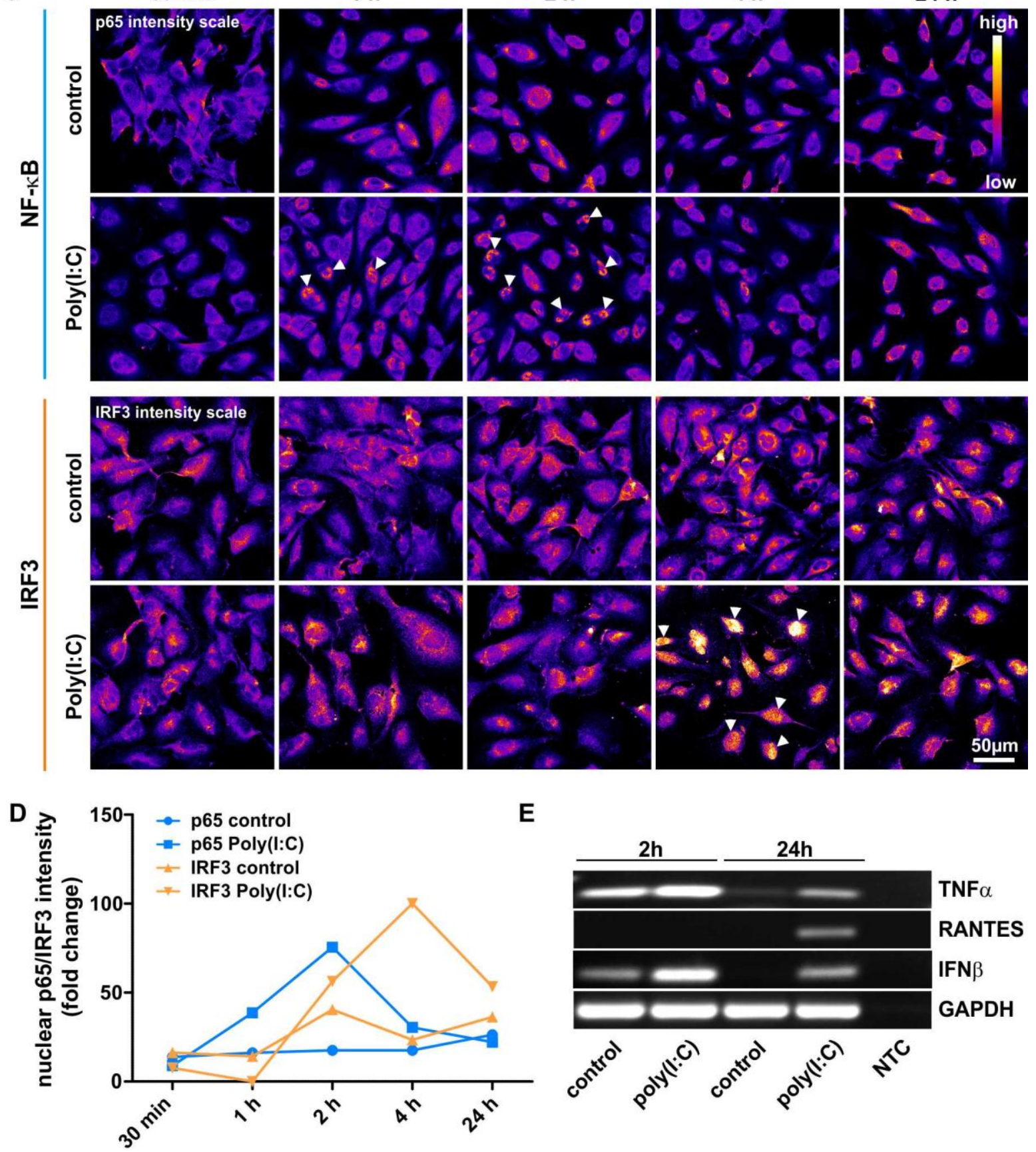

E

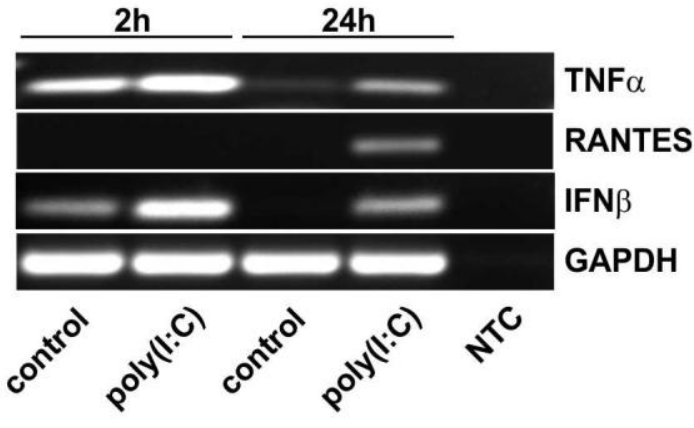


Figure 1. Double strand RNA analogue Poly(l:C) leads to increased activity of NF-KB and IRF3. (A) RT-PCR revealed expression of transcripts encoding proteins involved in NF-KBand IRF3 signalling in U251 cells. (B) Poly(I:C)-treatment resulted in significantly increased luciferase activities in U251 cells transiently transfected with TK(NF-KB) ${ }_{6} \mathrm{LUC}$ and $\mathrm{pRL}-\mathrm{CMV}$ vector or IRF3-GAL4, UAS-LUC and $\mathrm{pRL-CMV} \mathrm{vectors} \mathrm{in} \mathrm{comparison} \mathrm{to} \mathrm{untreated} \mathrm{control.}$ ( ${ }^{* * *} p<0.001$ was considered significant; unpaired t-test, two tailed, confidence interval: $95 \%$.) (C-D) Quantification of fluorescence intensities of immunocytochemical staining (displayed as intensity scale) depicting significantly increased nuclear localization of NF-KB p65 and IRF3 in U251 cells after Poly(I:C)-treatment compared to untreated controls (data merged of three independent measurement, ${ }^{* * *} p<0.001$ was considered significant). (E) RT-PCR showing increased expression levels of the NF-KB target gene TNFa as well as IRF3 target genes RANTES and IFN- $\beta$ after exposure to Poly $(\mathrm{I}: \mathrm{C})$ in comparison to untreated control. NTC: no template control. 
Figure 2

A

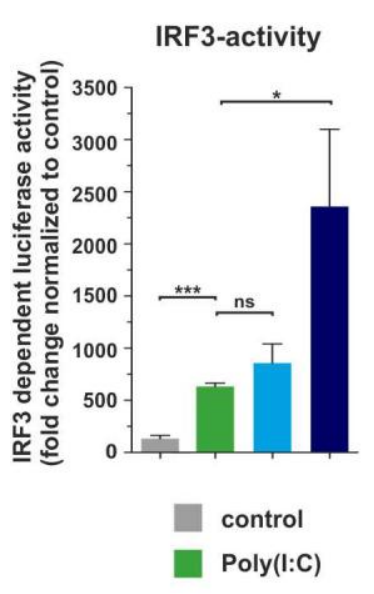

Poly(l:C)

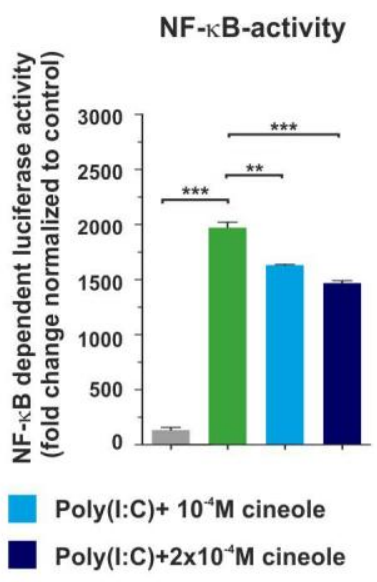

B

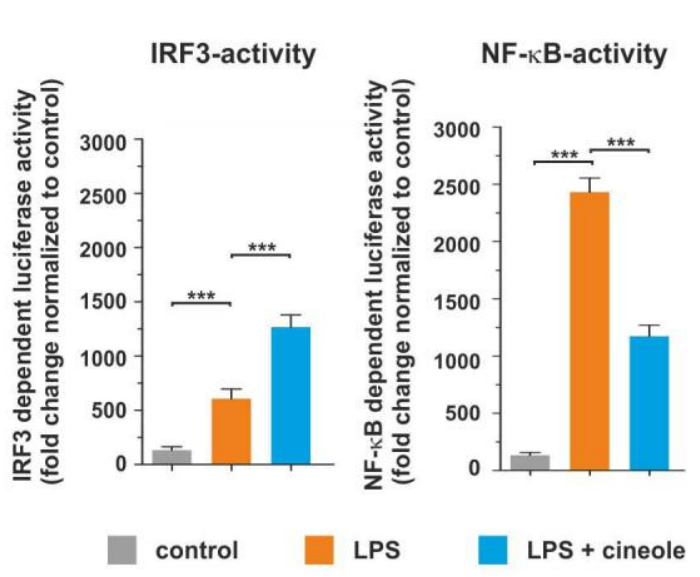

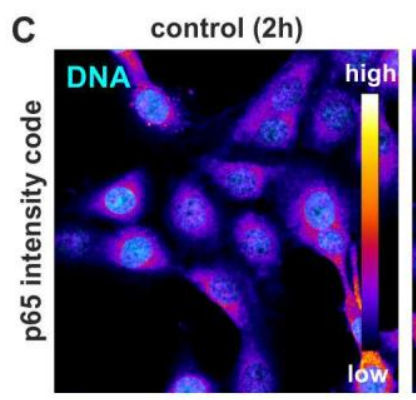

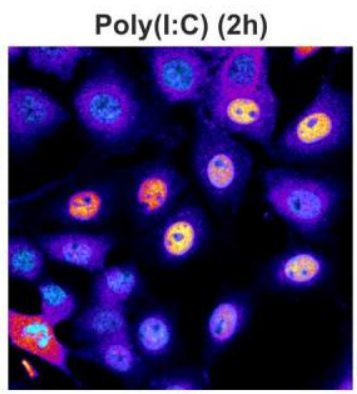

Poly(l:C)+cineole (2h)
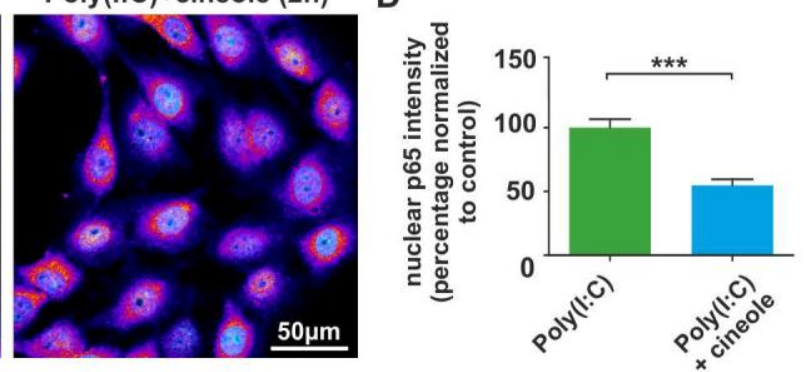

Figure 2. 1,8-cineole leads to increased IRF3-activity and reduced activity of NF-KB in U373 cells stimulated with Poly(I:C) or LPS. (A) Luciferase activity in U373 cells transiently transfected with IRF3-driven luciferase reporters was significantly increased after treatment with Poly $(\mathrm{I}: \mathrm{C})$ in comparison to untreated control. Co-treatment with Poly $(\mathrm{I}: \mathrm{C})$ and 1,8-cineole resulted in significantly increased luciferase activity when compared to the Poly(I:C)-treated approach. Significantly increased luciferase activity in U373 cells transiently transfected with NF-kB-dependent luciferase reporters after exposure to Poly $(\mathrm{I}: \mathrm{C})$ was significantly decreased after co-treatment with 1,8 -cineole. $\left({ }^{* * *} p<0.001,{ }^{* *} p<0.01\right.$ and ${ }^{*} p<0.05$ was considered significant, unpaired t-test, two tailed, confidence interval: 95\%. Data merged from two independent measurements.) (B) Treatment with LPS resulted in significantly increased luciferase activity in U373 cells transiently transfected with IRF3-luciferase reporters compared to untreated control. Co-treatment with LPS and 1,8-cineole resulted in significantly increased amounts of luciferase activity compared to the LPS-treated cells. U373 cells transiently transfected with NF-KB-driven luciferase reporters showed significantly increased luciferase activity after LPS-treatment, which was significantly decreased after cotreatment with 1,8 -cineole. $\left({ }^{* * *} p<0.001\right.$ and ${ }^{* *} p<0.01$ was considered significant, unpaired $t-$ test, two tailed, confidence interval: 95\%). Data merged from two independent measurements. (C-D) Amount of nuclear localized NF-kB p65 was significantly reduced in U373 cells after co-treatment with Poly $(\mathrm{I}: \mathrm{C})$ and 1,8-cineole in comparison to Poly $(\mathrm{l}: \mathrm{C})$ stimulation for $2 \mathrm{~h}$ (immunocytochemical stainings displayed as intensity scale; ${ }^{\star * *} \mathrm{p}<0.001$ was considered significant, unpaired t-test, two tailed, confidence interval: 95\%). 
Figure 3

A

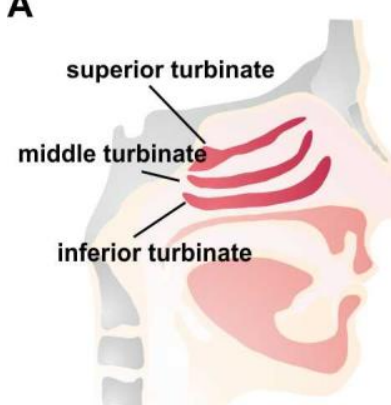

B

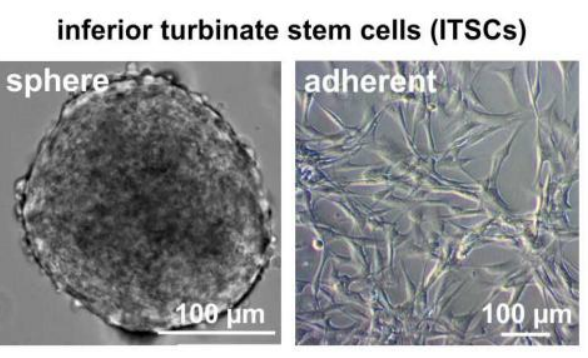

C

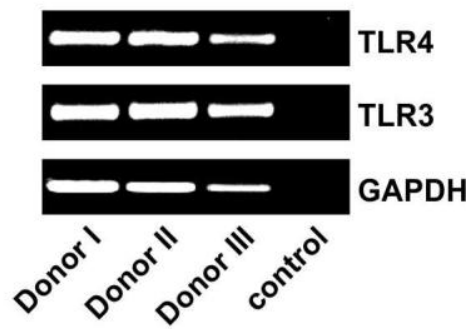

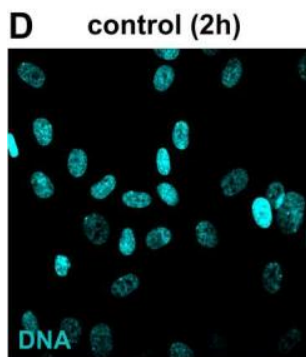
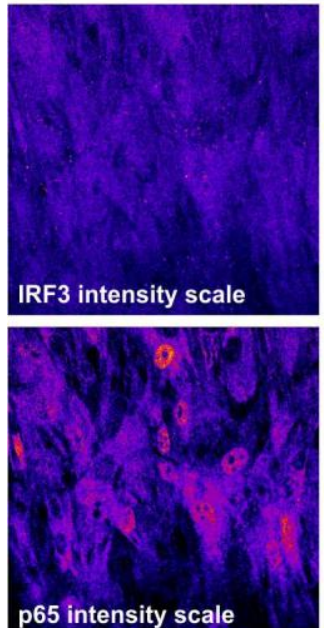

$\operatorname{Poly}(\mathrm{I}: \mathrm{C})(2 \mathrm{~h})$
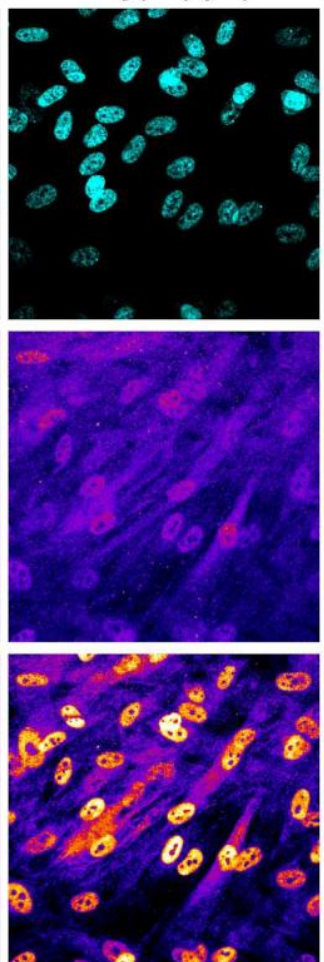
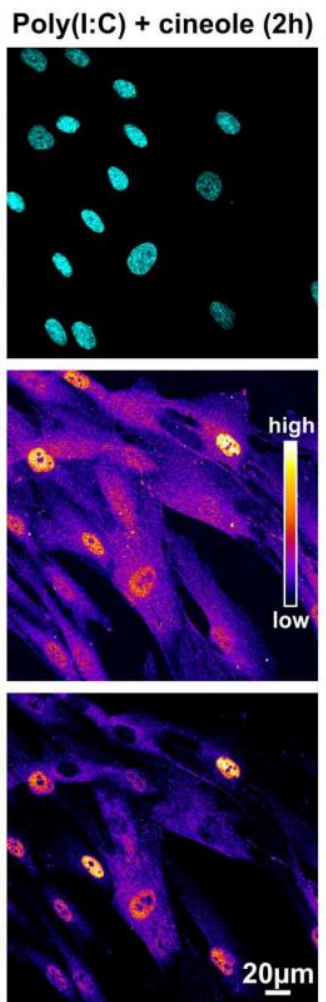

$E$

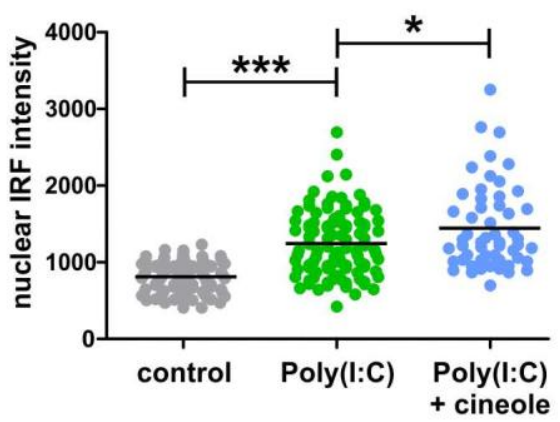

$\mathbf{F}$

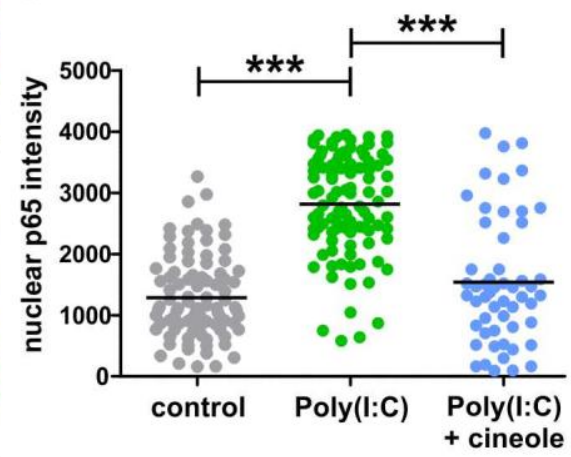

Figure 3. Inferior turbinate stem cells treated with Poly $(\mathrm{l}: \mathrm{C})$ show significantly increased IRF3-activity accompanied by significantly reduced NF-KB-activity after co-treatment with 1,8cineole. (A) Schematic view of the nasal cavity. (B) Isolated ITSCs cultivated as characteristic free-floating spheres and in an adherent state. (C) ITSCs expressed TLR3 and TLR4, relevant receptors of Poly(I:C)- and LPS-recognition. (D-E) Compared to control, Poly(I:C)-treatment of ITSCs for $2 \mathrm{~h}$ resulted in significantly increased nuclear translocation of IRF3 accompanied by significantly elevated amounts of nuclear localized NF-kB p65. Cotreatment with Poly(I:C) and 1,8-cineole led to further significantly increased nuclear translocation of IRF3 and significantly decreased amounts of nuclear localized NF-kB p65 in comparison to Poly(I:C)-stimulation. Immunocytochemical stainings are displayed as intensity scale; $\left({ }^{* * *} p<0.001,{ }^{* *} p<0.01\right.$ and ${ }^{*} p<0.05$ was considered significant, unpaired $t-$ test, two tailed, confidence interval: $95 \%)$. 
Figure 4


B

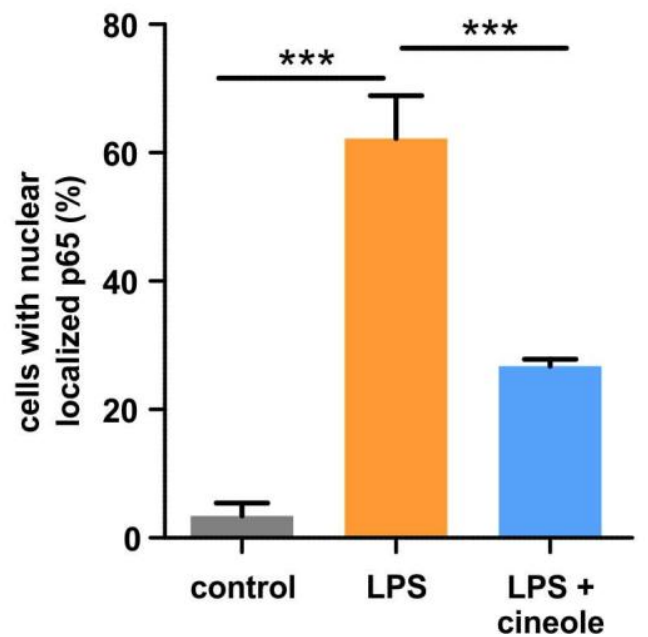

C

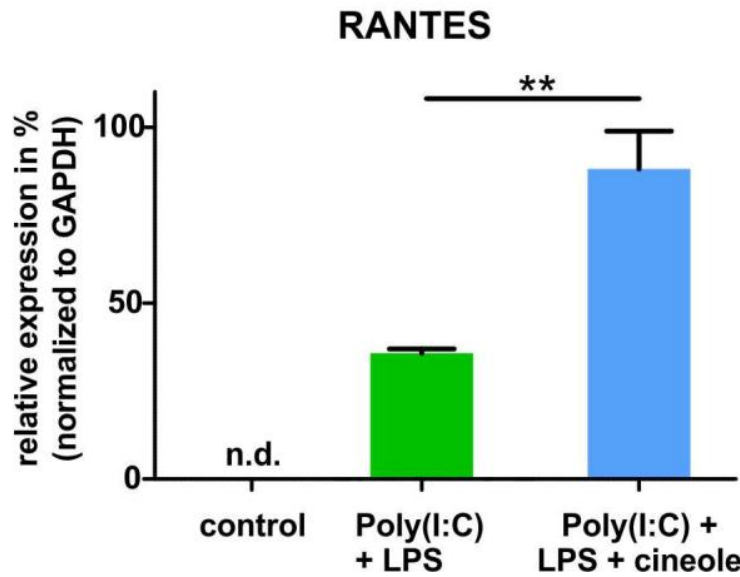

Figure 4. 1,8-cineole leads to significantly decreased activity of NF-KB in LPS-treated ITSCs and highly elevated expression of the IRF3 target gene RANTES in a model of superinfection. (A-B) LPS-treatment of ITSCs for $2 \mathrm{~h}$ led to a significantly elevated nuclear translocation of NF-KB p65, which was significantly decreased after co-treatment with 1,8cineole. Immunocytochemical staining displayed as intensity scale. (C) Real time PCR depicting significantly increased expression levels of the IRF3 target gene RANTES in ITSCs pre-treated with Poly $(\mathrm{I}: \mathrm{C})$ for $4 \mathrm{~h}$ followed by co-exposure to Poly $(\mathrm{I}: \mathrm{C})$ and LPS for $20 \mathrm{~h}$ in comparison to control. Co-treatment of ITSCs with Poly(I:C)/LPS and 1,8-cineole after Poly $(I: C)$ pre-treatment resulted further elevated expression levels of RANTES. n.d.: not detectable. $\left({ }^{* *} p<0.001\right.$ and ${ }^{* *} p<0.01$ was considered significant, unpaired t-test, two tailed, confidence interval: $95 \%)$. 
Figure 5

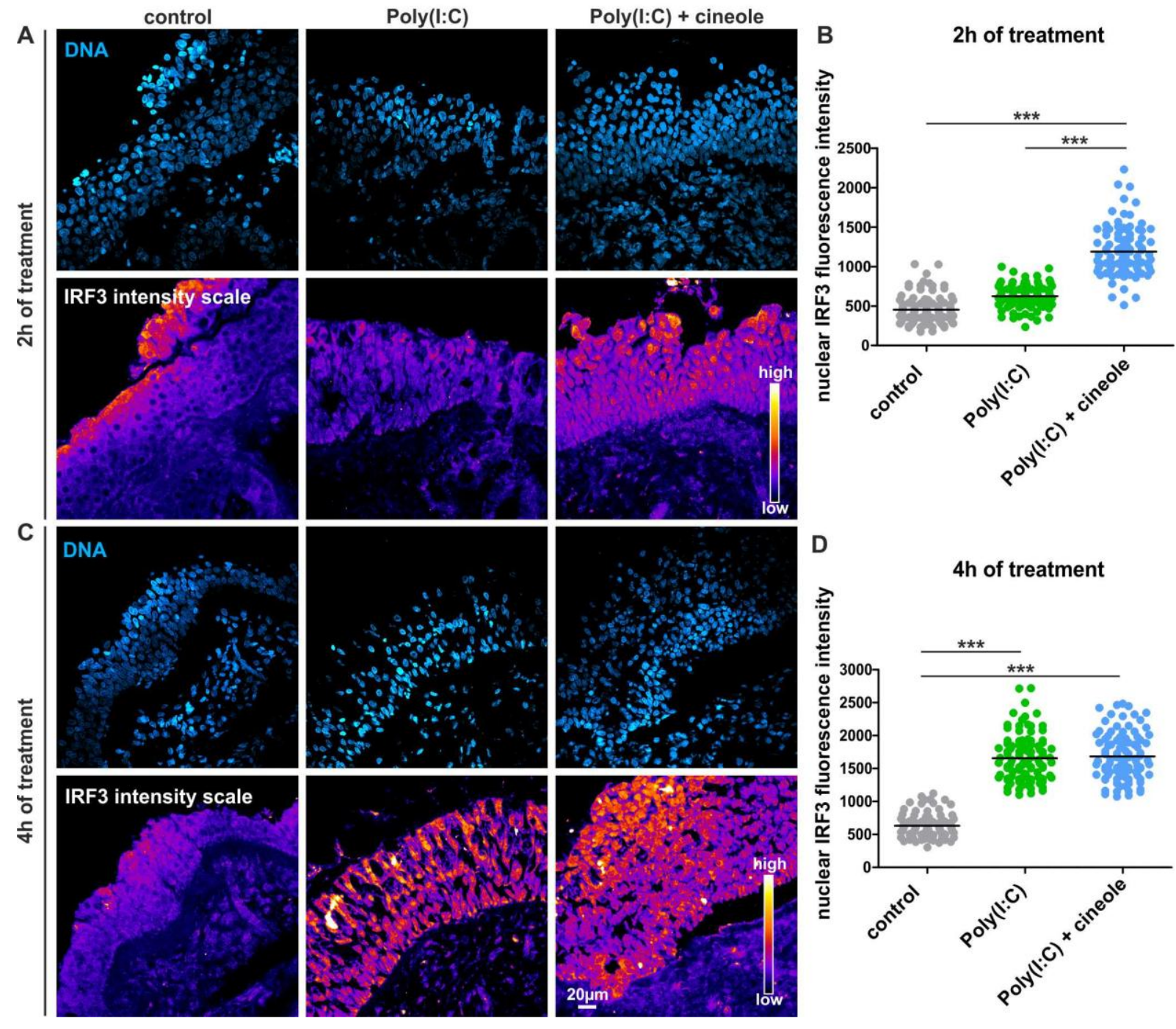

Figure 5. Ex vivo cultivated human nasal turbinate tissue stimulated with Poly(I:C) shows a significantly increased amount of nuclear IRF3 after co-treatment with 1,8-cineole. (A) Immunohistochemical stainings (displayed as intensity scale) of human nasal turbinate slice cultures showed increased amounts of nuclear localized IRF3 after $2 \mathrm{~h}$ of Poly(I:C)-treatment in comparison to untreated control, which was further increased after co-treatment with 1,8cineole. (B) Quantification of nuclear fluorescence intensities of immunohistochemical stainings revealed significantly increased nuclear localization of IRF3 after co-treatment with Poly $(\mathrm{I}: \mathrm{C})$ and 1,8-cineole for $2 \mathrm{~h}$ in comparison to Poly $(\mathrm{I}: \mathrm{C})$-treated approach and control. $\left({ }^{* *} p<0.001\right.$ was considered significant, unpaired t-test, two tailed, confidence interval: $\left.95 \%\right)$ (C) Increased nuclear translocation of IRF3 in Poly(I:C)-treated nasal slice cultures after $4 \mathrm{~h}$ was further increased after co-treatment with 1,8-cineole. (D) Quantification of nuclear fluorescence intensities of immunohistochemical stainings showed significantly increased nuclear localization of IRF3 after $4 \mathrm{~h}$ of Poly $(\mathrm{l}: \mathrm{C})$-treatment and co-treatment with Poly $(\mathrm{I}: \mathrm{C})$ and 1,8 -cineole compared to control $\left({ }^{* * *} \mathrm{p}<0.001\right.$ was considered significant, unpaired t-test, two tailed, confidence interval: 95\%). 
Figure 6

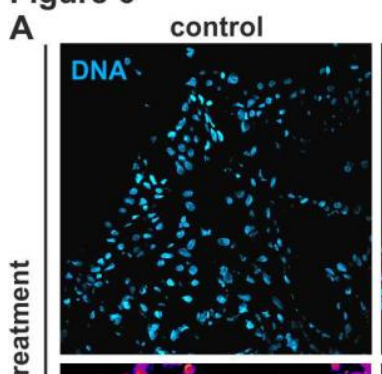

p65 intensity scale

ล

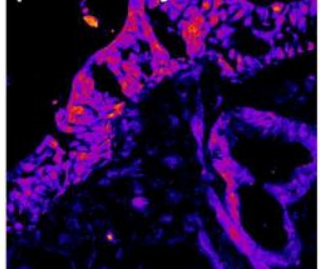

Poly(I:C)
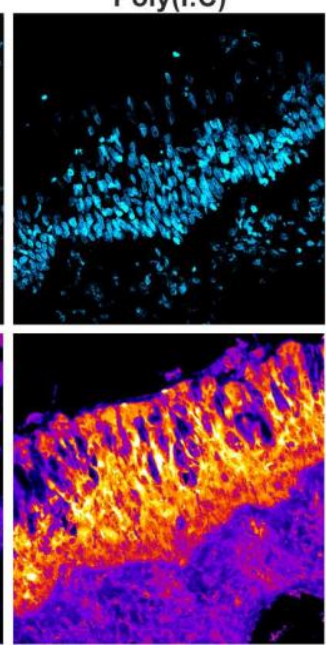

Poly(I:C) + cineole

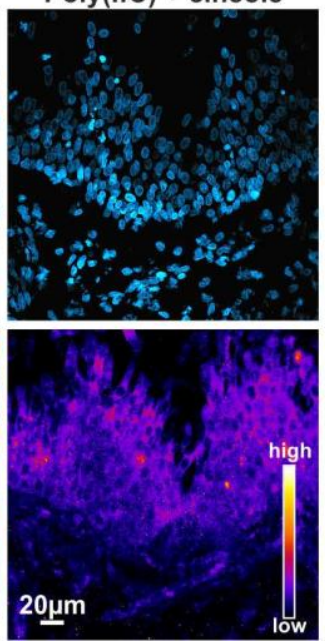

B

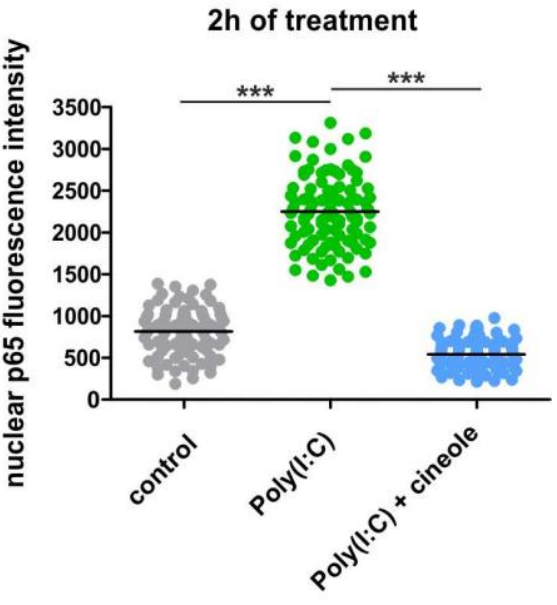

Figure 6. 1,8-cineole leads to a reduction in nuclear localized NF-KB of ex vivo cultivated human nasal turbinate slices after Poly(l:C)-dependent stimulation. (A) Immunohistochemical stainings (displayed as intensity scale) of human nasal turbinate slice cultures showed increased nuclear translocation of NF-KB p65 in Poly(l:C)-treated nasal slice cultures compared to control after $2 \mathrm{~h}$. Co-treatment with Poly $(\mathrm{I}: \mathrm{C})$ and 1,8-cineole for $2 \mathrm{~h}$ resulted in highly decreased NF-KB-activity. (B) Quantification of nuclear fluorescence intensities of immunohistochemical stainings revealed significantly increased nuclear localization of NF-KB p65 after $2 \mathrm{~h}$ of Poly(I:C)-treatment, which was significantly decreased after co-treatment with 1,8 -cineole $\left({ }^{* *} p<0.001\right.$ was considered significant, unpaired t-test, two tailed, confidence interval: $95 \%)$. 
Figure 7
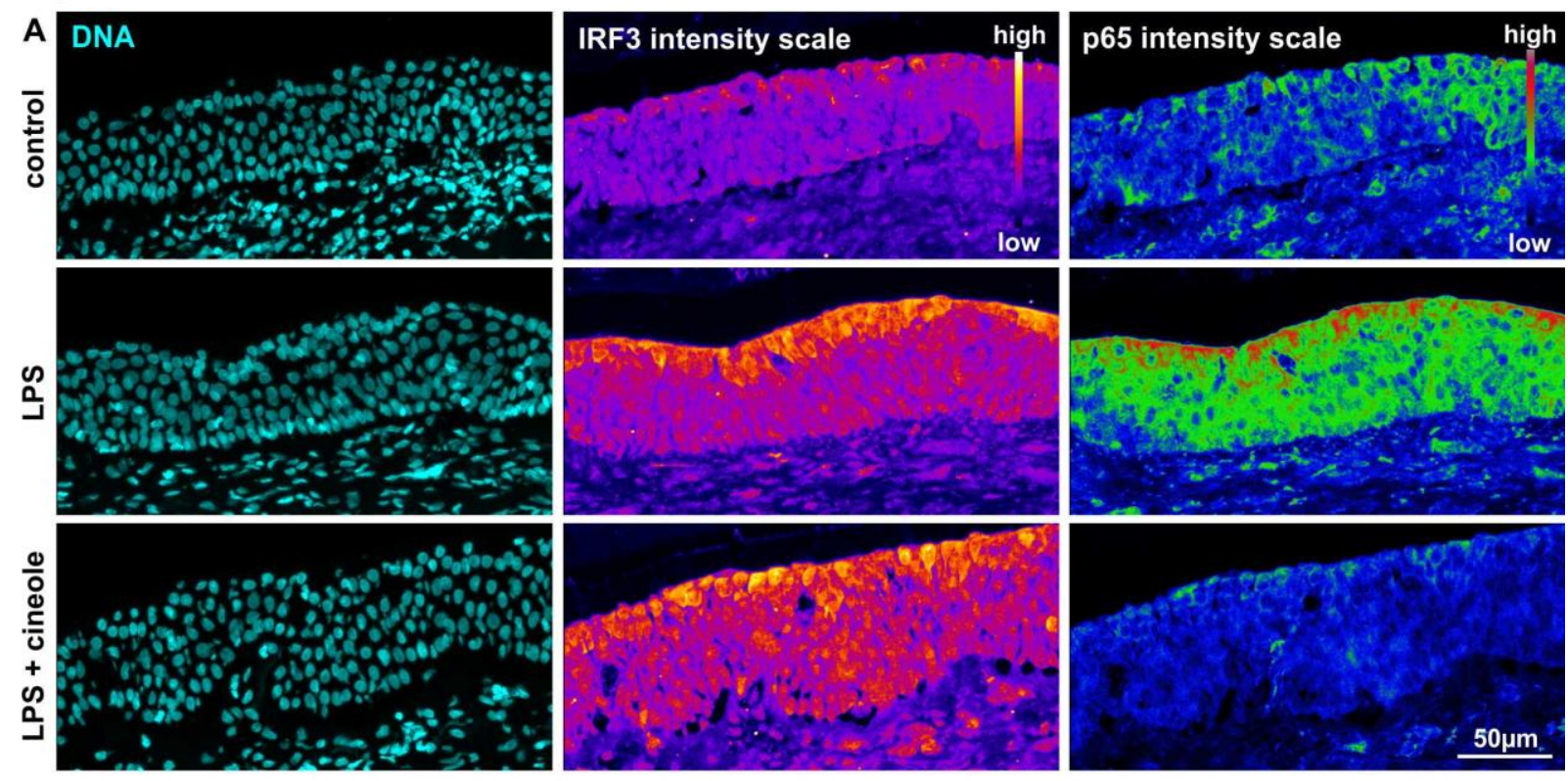

B

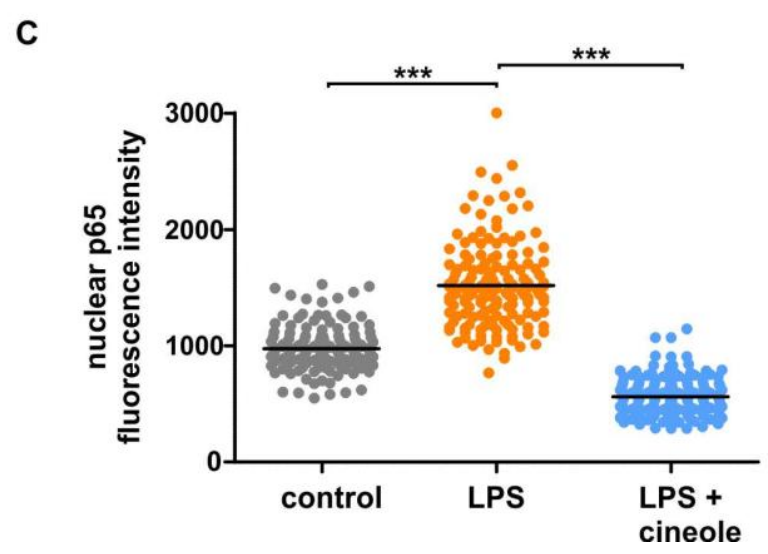

Figure 7. Ex vivo-cultivated human nasal turbinate slices stimulated with LPS show increased IRF3-activity and decreased NF-KB activity after co-treatment with 1,8-cineole. (A) Immunohistochemical analysis (displayed as intensity scale) of human nasal slice cultures depicting increased fluorescence intensity of IRF3 and NF-KB p65 after LPS-treatment in comparison to control. Co-treatment with LPS and 1,8-cineole resulted in increased nuclear fluorescence intensity of IRF3 as well as decreased NF-KB p65 nuclear fluorescence intensity compared to LPS-stimulated approach. (B-C) Quantification of nuclear fluorescence intensity of cells in the epithelial layer of cultured human nasal turbinates showed significantly increased nuclear localization of IRF3 and NF-KB p65 after LPS-treatment compared to control. Nuclear localization of IRF3 was significantly increased after cotreatment with LPS and 1,8-cineole in comparison to control, while the amount of nuclear localized NF-KB p65 was significantly decreased in comparison to the LPS-approach. $\left({ }^{* * *} p<0.001\right.$, unpaired t-test, two tailed, confidence interval: $\left.95 \%\right)$. 


\section{Supplementary figures}

Figure S1
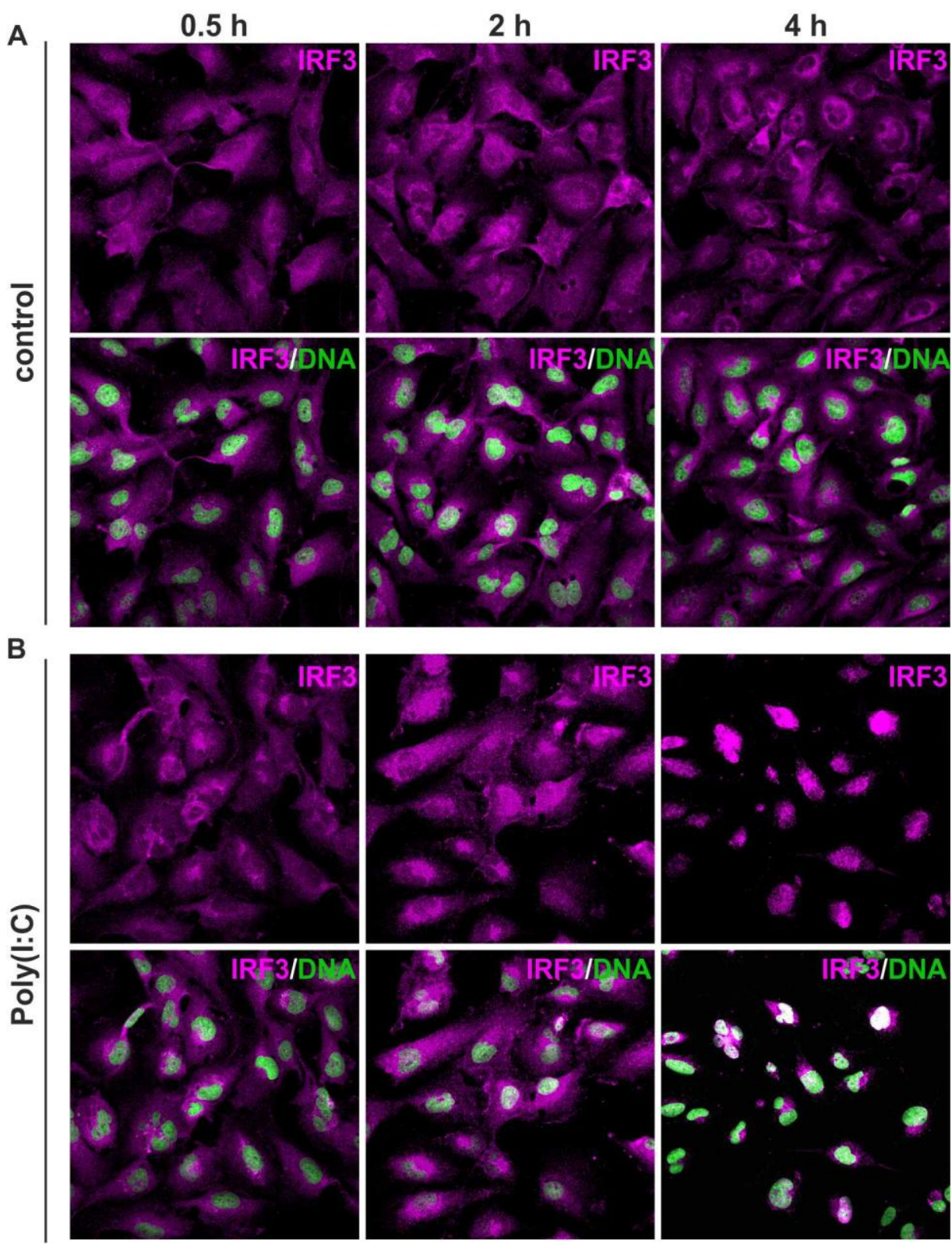

Figure S1. Poly(I:C) leads to increased nuclear localization of IRF3. Immunocytochemical stainings (see also Fig. 1C) not depicted as intensity scale showed nuclear localization of IRF3 by overlay with the DNA-counterstaining. In comparison to untreated controls (A), Poly(I:C)-treatment for $4 \mathrm{~h}$ led to increased nuclear localization of IRF3 in U251 cells (B). 
Figure S2

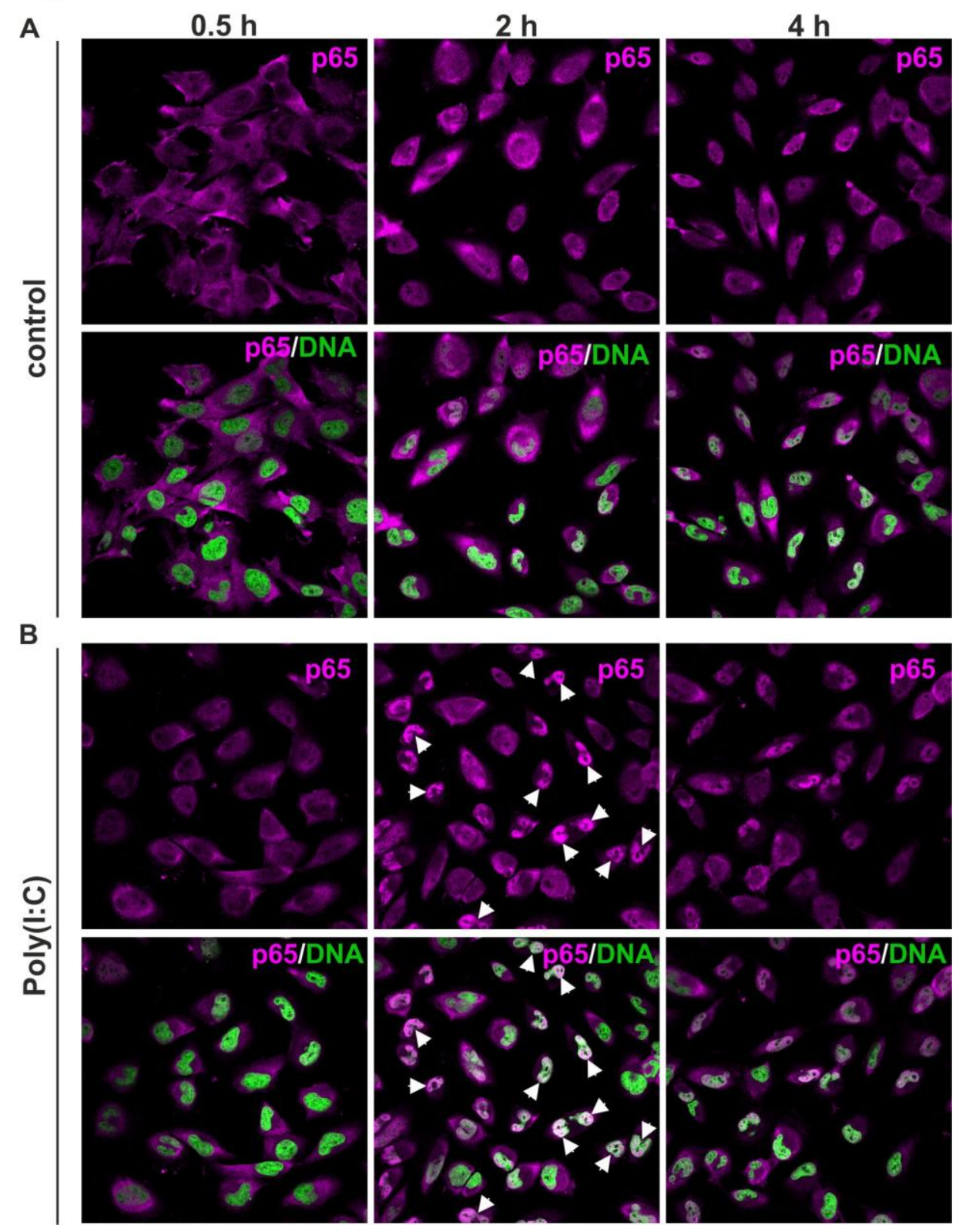

Figure S2. Poly(l:C) leads to increased nuclear localization of NF-kB p65. Immunocytochemical stainings (see also Fig. 1C) not depicted as intensity scale showed nuclear localization of NF-KB p65 by overlay with the DNA-counterstaining. In comparison to untreated controls $(A)$, Poly $(\mathrm{l}: \mathrm{C})$-treatment for $2 \mathrm{~h}$ led to increased nuclear localization of NF$\mathrm{KB}$ p65 in U251 cells (B). 
Figure S3

A

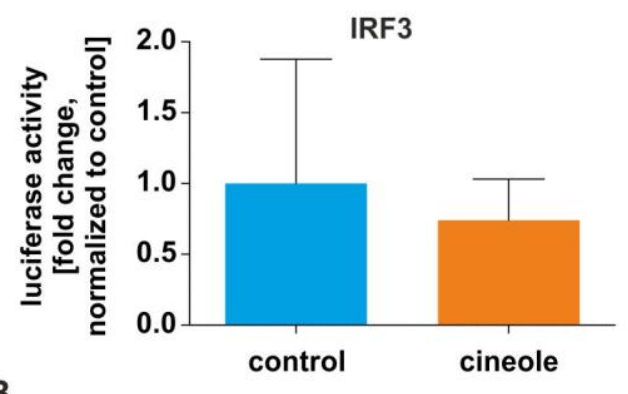

B

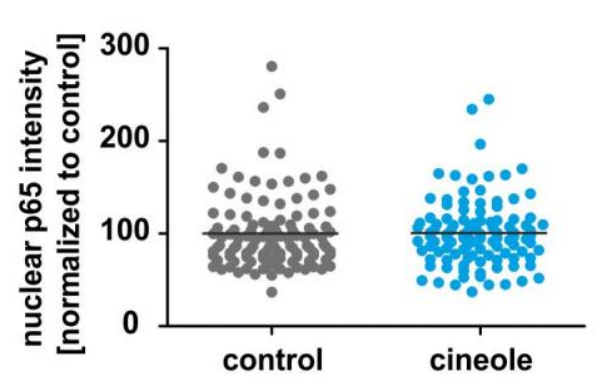

C
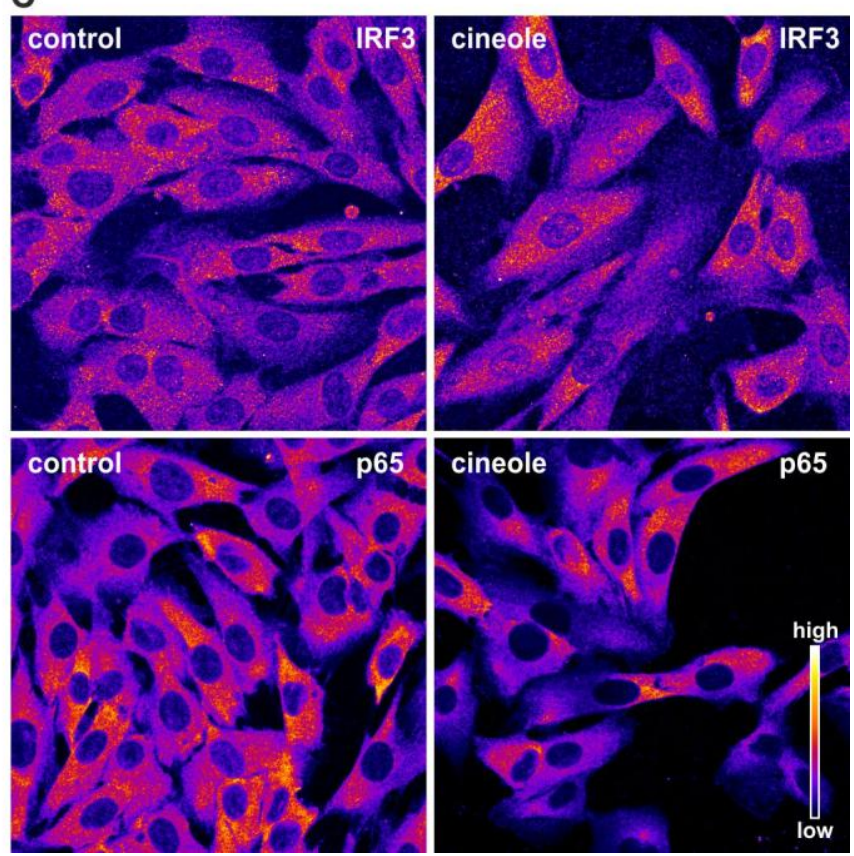

Figure S3. 1,8-cineole alone does not lead to altered IRF3- and NF-KB-activity in U373 cells and ITSCs. (A) Luciferase activity in U373 cells transiently transfected with IRF3-GAL4 and UAS-LUC vectors was not increased after treatment with 1,8-cineole in comparison to untreated control. (B) Amount of nuclear localized NF-KB p65 was not reduced in U373 cells after treatment with 1,8-cineole in comparison to control. (C) ITSCs showed no changes of nuclear translocation of IRF3 and NF-KB after treatment with 1,8-cineole for $4 \mathrm{~h}$ in comparison to control. 
Figure S4

A

control

LPS
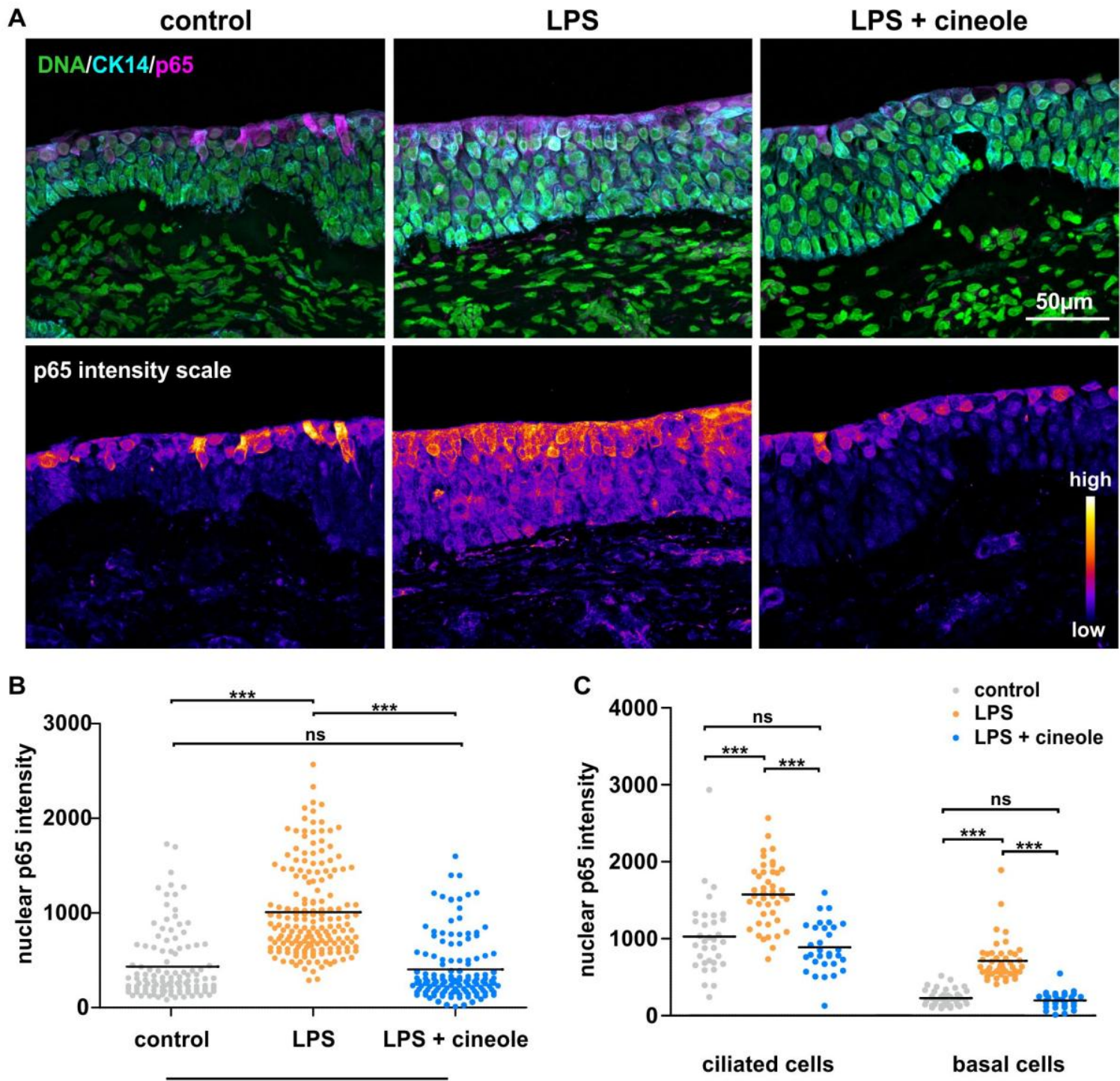

epithelial layer

Figure S4. LPS-dependent nuclear localization of NF-KB p65 in the epithelial layer of ex vivo cultivated human nasal turbinate slices is strongly attenuated after exposure to 1,8-cineole. (A) Immunohistochemical stainings of cultivated human nasal turbinate tissue revealed CK14-positive intact epithelial layer showing increased nuclear translocation of NF-KB p65 after LPS-treatment, which was reduced after co-treatment with 1,8-cineole. (B-C) Quantification of fluorescence intensities of the immunohistochemical stainings revealed a significant increase in the amount of nuclear localized NF-KB p65 in the whole epithelial layer and specifically in ciliated as well as in basal cells after LPS-treatment, which was significantly decreased after co-treatment with 1,8 -cineole $\left({ }^{* * *} \mathrm{p}<0.001\right.$, unpaired t-test, two tailed, confidence interval: 95\%). 